\title{
Characteristic Analysis and Optimization of a Four- bar Compliant Mechanism with Single Flexible Member
}

Shanzeng Liu ( $\square$ liushanzeng@163.com )

China University of Mining and Technology https://orcid.org/0000-0002-9174-8174

\section{Zhaopeng Sun}

China University of Mining Technology: China University of Mining and Technology

\section{Gang Shen}

China University of Mining Technology: China University of Mining and Technology

\section{Yunwang Li}

China University of Mining Technology: China University of Mining and Technology

\section{Original Article}

Keywords: compliant mechanism, pseudo-rigid body model, bistable characteristics, energy method, optimal design

Posted Date: April 13th, 2021

DOI: https://doi.org/10.21203/rs.3.rs-397919/v1

License: (9) This work is licensed under a Creative Commons Attribution 4.0 International License. Read Full License 
DOI: 10.3901/CJME.2014.0320.001, available online at www.springerlink.com; www.cjmenet.com; www.cjmenet.com.cn

\title{
Characteristic analysis and optimization of a four-bar compliant mechanism with single flexible member
}

\author{
LIU Shanzeng*, SUN Zhaopeng, SHEN Gang, and LI Yunwang \\ School of Mechanical and Electrical Engineering, China University of Mining and Technology, Xuzhou, 221116, \\ China
}

Received March 1, 2014; revised June 17, 2014; accepted August 17, 2014

\begin{abstract}
The characteristics and optimization analysis of a four-bar compliant mechanism with one flexible member (or flexible joint) are carried out. Firstly, based on the pseudo-rigid body model theory of the compliant mechanism, the kinematics relationship, system kinetic energy and potential energy of the general four-bar compliant mechanism are analyzed, and the dynamic model of the four-bar compliant mechanism is established by using Lagrange's equation. Secondly, through the creation of the energy equation of the four-bar compliant mechanism and the analysis of the first and second derivatives of the input variables, the parametric conditions for the existence of the bistable characteristics of the four-bar compliant mechanism with one flexible member are proposed. Then, taking the compliant bistable switch as an example, the internal relations between the driving characteristics of the four-bar compliant mechanism, the initial motion position of the mechanism and the parameters of the flexible member are explored. Finally, based on the improvement of the performance of the compliant bistable switch, the optimization analysis of the maximization of the motion range of the driving link and the maximization of the deformation energy of the flexible member are carried out. The research provides a theoretical basis for the product development and control of a bistable four-bar compliant mechanism.
\end{abstract}

Keywords: compliant mechanism, pseudo-rigid body model, bistable characteristics, energy method, optimal design

\section{Introduction*}

Compliant mechanism is a kind of mechanical device that realizes movement, force and energy transfer or conversion by the deformation of flexible members ${ }^{[1]}$. In recent years, it has received great attention in the fields of MEMS device design, bioengineering micro-operation, self-reconfigurable dextrous manipulator, multi-channel analog switch, aerospace and other fields.

Around 1995, HOWELL, et $\mathrm{al}^{[2]}$, proposed the concept of pseudo-rigid body model, which promoted the development of compliant mechanism. JENSEN, et $\mathrm{al}^{[3]}$,analyzed the bistable characteristics of four-link

\footnotetext{
${ }^{*}$ Corresponding author. E-mail:liushanzeng@163.com Supported by the Priority Academic Program Development of Jiangsu Higher Education Institutions (PAPDJX02).

(C) Chinese Mechanical Engineering Society and Springer-Verlag Berlin Heidelberg 2014
}

compliant mechanisms based on the pseudo-rigid body model, and obtained a large class of four-link compliant bistable mechanisms with one flexible joint. $\mathrm{HAN}^{[4]}$ proposed a tension-compression combined bistable mechanism and carried out kinematic static analysis of the beam constraint model and the chain beam constraint model. TODD, et $\mathrm{al}^{[5]}$, developed a sensor based on a fully compliant bistable mechanism to record whether the package was hit during transportation, so as to understand the impact status of the goods without unwrapping the package. Inspired by the structure of auditory hair bundle, KIM, et $\mathrm{al}^{[6]}$,studied a compliant bistable mechanism energy harvester, which can be used to collect low-frequency vibration energy. JUNG, et al ${ }^{[7]}$, designed a bistable jumping mechanism for robots, the device was triggered by shape memory alloy actuator, and large energy could be released at the moment of jumping, thus improving the jumping height of the robot. CHALVET, et a ${ }^{[8]}$, developed a digital microrobot based 
on four bistable modules. Due to the use of a bistable mechanism, the precise micro-positioning of the robot was realized by only open-loop control. HETRIK, et $\mathrm{al}^{[9]}$, adopted the topology optimization method and took satisfying the motion constraints and maximizing the energy as the objective function to carry out the optimization analysis of the compliant mechanism. ZHAN, et $\mathrm{al}^{[10]}$, evaluated the static strength of the structure with the sum of the magnitude of the signed von Mises stress and the mean absolute value, and used the modified Goodman fatigue criteria to evaluate the structural fatigue strength. Then, the $\mathrm{P}$ norm approach was used to approximate the local element stresses, and the optimization analysis of the continuum structure was carried out. Based on the principle of compliant mechanism, Wang, et $\mathrm{al}^{[11]}$, discussed the structural design of dielectric elastomer actuator by using topology optimization method. PEI, et al ${ }^{[12]}$, discussed the design of compliant straight-line mechanisms using flexural joints. WANG, et al ${ }^{[13]}$, adopted the finite element method and Lagrange equation to carry out the dynamic modeling of the plane compliant mechanism and the dynamic stress analysis of the flexible element. LI, et $\mathrm{al}^{[14]}$, summarized the electroactive bistable mechanism and introduced the electroactive bistable mechanism with in-plane mode and out-of-plane mode with respect to the motion direction and its application in soft robot.

In this paper, based on the pseudo-rigid body model theory, the conditions for the bistable characteristics of a four-bar compliant mechanism with one flexible member are derived by using the energy method. Combining with an application example of a compliant bistable switch, the driving characteristics and mechanism parameters of the four-bar compliant mechanism are optimized.

\section{Dynamic analysis}

A four-bar compliant mechanism and its pseudo-rigid body model are shown in Fig. 1. The four-bar compliant mechanism consists of two flexible members (ie, links 2 and 4) and a rigid member (ie, link 3 ). The length of the link 2 , the link 3 and the link 4 is denoted as $l_{\mathrm{i}}(i=2,3,4)$ and the mass is denoted as $m_{i}(i=2,3,4)$, and the moment of inertia with respect to the center of mass is denoted as $J_{i}(i=2,3,4)$. The pseudo-rigid body model contains four torsional springs, and the dynamic spring constant of the torsional springs is denoted as $K_{\mathrm{d} i}(i=1,2,3,4)$.

Using $\gamma$ to represent the characteristic radius factor of the flexible member, then the rotation radii of the equivalent members 2 and 4 in the pseudo-rigid body model can be expressed as $r_{2}=\gamma_{2} l_{2}$ and $r_{4}=\gamma_{4} l_{4}$, respectively, and the centroids of the equivalent members 2, 4 and link 3 are denoted as $S_{2}, S_{4}$ and $S_{3}$, respectively.

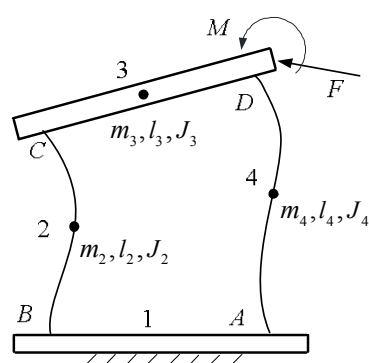

(a) Structural diagram

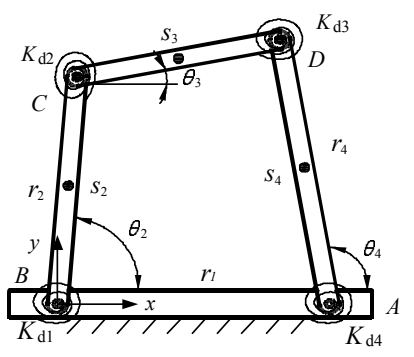

(b) Pseudo-rigid body model
Fig. 1. Four-bar compliant mechanism

\subsection{Kinematics}

The rotation angle, angular velocity and angular acceleration of the link 2 in Fig. 1(b) are represented by $\theta_{2}, \omega_{2}=\dot{\theta}_{2}$ and $\ddot{\theta}_{2}$ respectively. Taking point $B$ as the origin of the coordinates and establishing a Cartesian coordinate system as shown in Fig. 1(b), we get

$$
\left\{\begin{array}{l}
r_{2} \cos \theta_{2}+r_{3} \cos \theta_{3}=r_{1}+r_{4} \cos \theta_{4} \\
r_{2} \sin \theta_{2}+r_{3} \sin \theta_{3}=r_{4} \sin \theta_{4}
\end{array}\right.
$$

Taking $\theta_{2}$ as a variable and solving Eq. (1), we have

$$
\begin{gathered}
\theta_{3}=2 \arctan \frac{b \pm \sqrt{a^{2}+b^{2}-c^{2}}}{a+c} \\
\theta_{4}=2 \arctan \frac{b \pm \sqrt{a^{2}+b^{2}-d^{2}}}{a+d} \\
a=\cos \theta_{2}-\frac{r_{1}}{r_{2}} \quad c=\frac{r_{4}^{2}-r_{1}^{2}-r_{2}^{2}-r_{3}^{2}+2 r_{1} r_{2} \cos \theta_{2}}{2 r_{2} r_{3}} \\
b=\sin \theta_{2} \quad d=\frac{r_{1}^{2}+r_{4}^{2}+r_{2}^{2}-r_{3}^{2}-2 r_{1} r_{2} \cos \theta_{2}}{2 r_{2} r_{4}}
\end{gathered}
$$

At the same time, the first derivative of Eq. (1) with respect to time $t$ can be obtained

$$
\begin{gathered}
\omega_{3}=\frac{r_{2} r_{3} \sin \left(\theta_{3}-\theta_{2}\right)+r_{1} r_{2} \sin \theta_{2}}{r_{2} r_{3} \sin \left(\theta_{3}-\theta_{2}\right)-r_{1} r_{3} \sin \theta_{3}} \omega_{2} \\
\omega_{4}=\frac{r_{2} r_{4} \sin \left(\theta_{4}-\theta_{2}\right)+r_{1} r_{2} \sin \theta_{2}}{-r_{2} r_{4} \sin \left(\theta_{4}-\theta_{2}\right)+r_{1} r_{4} \sin \theta_{4}} \omega_{2}
\end{gathered}
$$

Suppose the link 3 is a homogeneous bar with uniform cross section, and its centroid coordinate is $\left(x_{3}, y_{3}\right)$, then

$$
\left\{\begin{array}{l}
x_{3}=r_{2} \cos \theta_{2}+\frac{1}{2} r_{3} \cos \theta_{3} \\
y_{3}=r_{2} \sin \theta_{2}+\frac{1}{2} r_{3} \sin \theta_{3}
\end{array}\right.
$$

From Eq. (6), the centroid velocity $V_{\mathrm{S} 3}$ of the link 3 can be expressed as

$$
V_{\mathrm{S} 3}^{2}=r_{2}^{2} \omega_{2}^{2}+\frac{1}{4} r_{3}^{2} \theta_{3}^{2}+r_{2} r_{3} \cos \left(\theta_{2}-\theta_{3}\right) \omega_{2} \omega_{3}
$$

Similarly, the centroid velocities $V_{\mathrm{S} 2}$ and $V_{\mathrm{S} 4}$ of the link 2 and link 4 can be expressed as

$$
\left\{\begin{array}{l}
V_{\mathrm{S} 2}=\frac{1}{2} r_{2} \omega_{2} \\
V_{\mathrm{S} 4}=\frac{1}{2} r_{4} \omega_{4}
\end{array}\right.
$$




\subsection{Kinetic energy of system}

The kinetic energy $E_{\mathrm{k} 2}, E_{\mathrm{k} 3}$ and $E_{\mathrm{k} 4}$ of the links 2, 3 and 4 in the four-bar compliant mechanism can be expressed as follows

$$
\begin{gathered}
E_{\mathrm{k} 2}=\frac{1}{2} m_{2} V_{\mathrm{S} 2}^{2}+\frac{1}{2} J_{2} \omega_{2}^{2} \\
E_{\mathrm{k} 3}=\frac{1}{2} m_{3} V_{\mathrm{S} 3}^{2}+\frac{1}{2} J_{3} \omega_{3}^{2} \\
E_{\mathrm{k} 4}=\frac{1}{2} m_{4} V_{\mathrm{S} 4}^{2}+\frac{1}{2} J_{4} \omega_{4}^{2}
\end{gathered}
$$

Hence, the total kinetic energy $E_{\mathrm{k}}$ of the four-bar compliant mechanism is given by

$$
E_{\mathrm{k}}=\sum_{i=2}^{4} E_{\mathrm{k} i}
$$

\subsection{Potential energy of system}

If the energy loss caused by the deformation of the flexible member and the friction between the members are ignored, then the elastic potential energy $E_{\mathrm{p}}$ stored by the flexible member is equal to the work done by the forces and moments acting on the member.

When the end of the flexible link is subjected to a moment $M$, as shown in Fig.1. Assuming that the pseudo-rigid body angle $\varphi=0$ when the flexible link is in the initial position, the angle that the end of the flexible link has rotated after being acted on by the moment $M$ is $\theta$. Then the elastic potential energy $E_{\mathrm{p} 1}$ of the flexible link can be expressed as

$$
\begin{gathered}
E_{\mathrm{p} 1}=\int_{0}^{\theta} M \mathrm{~d} \theta=\int_{0}^{\varphi} c_{\theta} M \mathrm{~d} \varphi \\
M=\gamma K_{\varphi} \frac{E I}{l} \varphi
\end{gathered}
$$

where $c_{\theta}$ denotes the parametric angle coefficient, $K_{\varphi}$ denotes the torsion spring stiffness coefficient, and $l$ denotes the length of the flexible link.

When the end of the flexible link is subjected to a force $F$, as shown in Fig.1. If the displacement of the end of the flexible link under the action of the force $F$ is $s$. Then the elastic potential energy $E_{\mathrm{p} 2}$ of the flexible link can be expressed as

$$
E_{\mathrm{p} 2}=\int_{0}^{s} F \mathrm{~d} s=\int_{0}^{\varphi} F_{\mathrm{t}} \gamma l \mathrm{~d} \varphi
$$

where $F_{\mathrm{t}}$ denotes the tangential component of the force $F$ along the trajectory of the end of the flexible link, namely

$$
F_{\mathrm{t}}=K_{\varphi} \varphi \frac{E I}{l^{2}}
$$

It is not difficult to obtain from equations (13) - (16) that the unified expression of the elastic potential energy of the equivalent dynamic model of the flexible link is

$$
E_{\mathrm{p} i}=\frac{1}{2} K_{\mathrm{d} i} \varphi_{i}^{2}
$$

where, $\varphi_{i} \quad(i=1,2,3,4)$ and $K_{\mathrm{d} i}(i=1,2,3,4)$ are the pseudo-rigid body angle and the dynamic spring constant of the torsion spring at the $i$ th joint of the mechanism, respectively.

So the elastic potential energy $E_{\mathrm{p}}$ of the mechanism can be expressed as

$$
E_{\mathrm{p}}=\sum_{i=1}^{4} E_{\mathrm{p} i}=\frac{1}{2} \sum_{i=1}^{4} K_{\mathrm{d} i} \varphi_{i}{ }^{2}=\frac{1}{2} \sum_{i=1}^{4} K_{\mathrm{d} i} \phi_{i}^{2}
$$

where, $\phi_{i}(i=1,2,3,4)$ denotes the rotation angle of the torsion spring at the $i$ th joint in the mechanism. Assuming that the position angle of the $i$ th link is $\theta_{i 0}$ $(i=2,3,4)$ when the torsion spring is not deformed, we have

$$
\left\{\begin{array}{l}
\phi_{1}=\theta_{2}-\theta_{20} \\
\phi_{2}=\left(\theta_{2}-\theta_{20}\right)-\left(\theta_{3}-\theta_{30}\right) \\
\phi_{3}=\left(\theta_{4}-\theta_{40}\right)-\left(\theta_{3}-\theta_{30}\right) \\
\phi_{4}=\theta_{4}-\theta_{40}
\end{array}\right.
$$

\subsection{Dynamics}

The Lagrange's equations of the second kind is expressed as

$$
\frac{\mathrm{d}}{\mathrm{d} t}\left(\frac{\partial L}{\partial \dot{\boldsymbol{q}}_{i}}\right)-\frac{\partial L}{\partial \boldsymbol{q}_{i}}=\boldsymbol{Q}_{i}
$$

where, $L$ denotes the Lagrangian function, $\boldsymbol{q}_{i}(i=1,2$, $3, \ldots, n)$ denotes the generalized coordinate variables of the system, $\boldsymbol{Q}_{i}$ denotes the generalized force.

By substituting equations (12) and (18) into Eq. (20) and simplifying, the dynamic equation of the four-bar compliant mechanism can be written as

$$
M_{\mathrm{e}} \ddot{\theta}_{2}+c \dot{\theta}_{2}^{2}+\varphi\left(\theta_{2}\right)=\tau_{i}
$$

where, $\tau_{i}$ denotes the generalized force of the mechanism, $M_{\mathrm{e}}, c$, and $\varphi\left(\theta_{2}\right)$ are functions of the structural parameters of the mechanism. From Eq. (21), the dynamic characteristics of the four-bar compliant mechanism (such as natural frequency, stress, etc.) can be solved.

\section{Analysis of bistable characteristics}

Eq. (1) takes the first and second derivatives of angle variable $\theta_{2}$, and solves and simplifies them, we get

$$
\begin{gathered}
\frac{\mathrm{d} \theta_{3}}{\mathrm{~d} \theta_{2}}=\frac{r_{2} \sin \left(\theta_{4}-\theta_{2}\right)}{r_{3} \sin \left(\theta_{3}-\theta_{4}\right)} \\
\frac{\mathrm{d} \theta_{4}}{\mathrm{~d} \theta_{2}}=\frac{r_{2} \sin \left(\theta_{3}-\theta_{2}\right)}{r_{4} \sin \left(\theta_{3}-\theta_{4}\right)} \\
\frac{\mathrm{d}^{2} \theta_{3}}{\mathrm{~d} \theta_{2}^{2}}=\frac{r_{2}}{r_{3}}\left[\frac{\cos \left(\theta_{4}-\theta_{2}\right)}{\sin \left(\theta_{3}-\theta_{4}\right)}\left(\frac{\mathrm{d} \theta_{4}}{\mathrm{~d} \theta_{2}}-1\right)-\right. \\
\left.\frac{\sin \left(\theta_{4}-\theta_{2}\right) \cos \left(\theta_{3}-\theta_{4}\right)}{\sin ^{2}\left(\theta_{3}-\theta_{4}\right)}\left(\frac{\mathrm{d} \theta_{3}}{\mathrm{~d} \theta_{2}}-\frac{\mathrm{d} \theta_{4}}{\mathrm{~d} \theta_{2}}\right)\right] \\
\frac{\mathrm{d}^{2} \theta_{4}}{\mathrm{~d} \theta_{2}^{2}=\frac{r_{2}}{r_{4}}}\left[\frac{\frac{\cos \left(\theta_{3}-\theta_{2}\right)}{\sin \left(\theta_{3}-\theta_{4}\right)}\left(\frac{\mathrm{d} \theta_{3}}{\mathrm{~d} \theta_{2}}-1\right)-}{\left.\frac{\sin \left(\theta_{3}-\theta_{2}\right) \cos \left(\theta_{3}-\theta_{4}\right)}{\sin ^{2}\left(\theta_{3}-\theta_{4}\right)}\left(\frac{\mathrm{d} \theta_{3}}{\mathrm{~d} \theta_{2}}-\frac{\mathrm{d} \theta_{4}}{\mathrm{~d} \theta_{2}}\right)\right]}\right.
\end{gathered}
$$


When a four-bar compliant mechanism contains one flexible member, without loss of generality, it is assumed that the torsion spring (or flexible joint) is located at the joint between the drived link and the frame, and its pseudo-rigid body model is shown in Fig. 2. According to equations (18) and (19), the energy equation of the mechanism can be written as

$$
E_{\mathrm{p}}=\frac{1}{2} K_{\mathrm{d} 4}\left(\theta_{4}-\theta_{40}\right)^{2}
$$

Eq. (26) finds the first and second derivatives of the variable $\theta_{2}$, we get

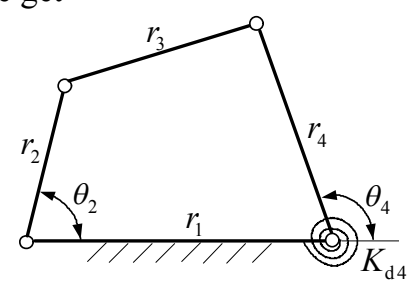

Fig. 2. Pseudo-rigid body model of four-bar compliant mechanism with one flexible member

$$
\begin{gathered}
\frac{\mathrm{d} E_{\mathrm{p}}}{\mathrm{d} \theta_{2}}=K_{\mathrm{d} 4}\left(\theta_{4}-\theta_{40}\right) \frac{\mathrm{d} \theta_{4}}{\mathrm{~d} \theta_{2}} \\
\frac{\mathrm{d}^{2} E_{\mathrm{p}}}{\mathrm{d} \theta_{2}^{2}}=K_{\mathrm{d} 4}\left(\theta_{4}-\theta_{40}\right) \frac{\mathrm{d}^{2} \theta_{4}}{\mathrm{~d} \theta_{2}^{2}}+K_{\mathrm{d} 4}\left(\frac{\mathrm{d} \theta_{4}}{\mathrm{~d} \theta_{2}}\right)^{2}
\end{gathered}
$$

Assuming $\sin \left(\theta_{3}-\theta_{4}\right) \neq 0$, combine Eq. (23) and Eq. (27), and set Eq. (27) equal to zero, we get

$$
\left\{\begin{array}{l}
\theta_{4}-\theta_{40}=0 \\
\text { or } \\
\sin \left(\theta_{3}-\theta_{2}\right)=0
\end{array}\right.
$$

According to Eq. (29), it is not difficult to obtain the solution of the mechanism in the equilibrium position as follows:

when $\theta_{4}=\theta_{40}$,

$$
\left\{\begin{array}{l}
\theta_{2}=\theta_{20} \\
\text { or } \\
\theta_{2}=2 \arctan \frac{r_{4} \sin \theta_{40}}{r_{1}+r_{4} \cos \theta_{40}}-\theta_{20}
\end{array}\right.
$$

when $\sin \left(\theta_{3}-\theta_{2}\right)=0$,

$$
\left\{\begin{array}{l}
\theta_{2}=\theta_{3} \\
\text { or } \\
\theta_{2}=\theta_{3} \pm \pi
\end{array}\right.
$$

Substitute the two values of $\theta_{2}$ in Eq. (30) into Eq. (28) respectively (in this case, in general $\theta_{2} \neq \theta_{3}$ ), and both can be obtained

$$
\frac{\mathrm{d}^{2} E_{\mathrm{p}}}{\mathrm{d} \theta_{2}^{2}}>0
$$

It can be seen that the configuration of the four-bar compliant mechanism corresponding to each value of $\theta_{2}$ in Eq. (30) is the stable equilibrium position.
Substituting the two values of $\theta_{2}$ in Eq. (31) into Eq. (28), we get

$$
\frac{\mathrm{d}^{2} E_{\mathrm{P}}}{\mathrm{d} \theta_{2}^{2}}=\left\{\begin{array}{l}
\frac{K_{\mathrm{d} 4} r_{2}\left(r_{2}+r_{3}\right)\left(\theta_{4}-\theta_{40}\right)}{r_{3} r_{4} \sin \left(\theta_{4}-\theta_{3}\right)},\left(\text { if } \theta_{2}=\theta_{3}\right) \\
\frac{K_{\mathrm{d} 4} r_{2}\left(r_{2}-r_{3}\right)\left(\theta_{4}-\theta_{40}\right)}{r_{3} r_{4} \sin \left(\theta_{4}-\theta_{3}\right)},\left(\text { if } \theta_{2}=\theta_{3} \pm \pi\right)
\end{array}\right.
$$

It can be seen from Eq. (32) that the bistable characteristics of the four-bar compliant mechanism are closely related to the size of each link, the position of the flexible joint and the initial motion position of the mechanism (i.e. the configuration of the mechanism without deformation of the flexible joint).

At the same time, if the four-bar compliant mechanism has bistable characteristics, then the mechanism should have an unstable equilibrium position between the two stable equilibrium positions. When $\theta_{2}=\theta_{3}$ and $\theta_{2}=\theta_{3} \pm \pi$ (where the \pm should be selected according to the mechanism parameters), it is not difficult to find that links 2 and 3 are in the collinear or overlapping collinear configuration (i.e., the singularity configuration of the mechanism) respectively. If the mechanism is slightly disturbed at this time, it will deviate from its original position. Therefore, it can be determined that $\theta_{2}=\theta_{3}$ and $\theta_{2}=\theta_{3} \pm \pi$ are the unstable equilibrium positions of the mechanism.

According to the foregoing analysis, it can be seen that if a four-bar compliant mechanism with one flexible member (or flexible joint) has bistable characteristics, then the mechanism should have a collinear configuration of the two links, and the torsion spring (i.e. flexible joint) must be installed on the opposite side of the two links with collinear configuration. In other words, the sum of the lengths of the two members connected to the flexible joint should be greater than the sum of the lengths of the other two members, or the difference between the lengths of the two members connected to the flexible joint is less than the difference between the lengths of the other two members. So, we have

$$
\left\{\begin{array}{l}
r_{\mathrm{a}}+r_{\mathrm{b}}>r_{\mathrm{c}}+r_{\mathrm{d}} \\
\text { or } \\
\left|r_{\mathrm{a}}-r_{\mathrm{b}}\right|<\left|r_{\mathrm{c}}-r_{\mathrm{d}}\right|
\end{array}\right.
$$

where, $r_{\mathrm{a}}, r_{\mathrm{b}}$ denote the lengths of the two members connected with the flexible joint, respectively, and $r_{\mathrm{c}}, r_{\mathrm{d}}$ denote the lengths of the other two members, respectively.

Corresponding to Eq. (33), the selection principle of the initial motion angle $\theta_{0}$ of the flexible joint without deformation is

$$
\begin{gathered}
\pi-\alpha_{1}<\theta_{0}<\pi-\alpha_{2} \\
\alpha_{1}=\arccos \frac{r_{\mathrm{a}}^{2}+r_{\mathrm{b}}^{2}-\left(r_{\mathrm{c}}+r_{\mathrm{d}}\right)^{2}}{2 r_{\mathrm{a}} r_{\mathrm{b}}}
\end{gathered}
$$




$$
\alpha_{2}=\arccos \frac{r_{\mathrm{a}}^{2}+r_{\mathrm{b}}^{2}-\left(r_{\mathrm{c}}-r_{\mathrm{d}}\right)^{2}}{2 r_{\mathrm{a}} r_{\mathrm{b}}}
$$

\section{Drive characteristic analysis}

The compliant bistable switch is a typical application of the four-bar compliant mechanism with single flexible member, as shown in Fig. 3. In the mechanism, positions $A, B$ and $C$ are hinges, member 2 is a driving link, and member 4 is a flexible link connected to the frame in the form of a cantilever beam. The angle between the frame and the horizontal plane is $\varphi=2^{\circ}$, the length and centroid of each member are respectively denoted as $l_{i}$ $(i=1,2,3,4)$ and $c_{i}(i=2,3,4)$, and the pseudo-rigid body model parameters, See Table 1.

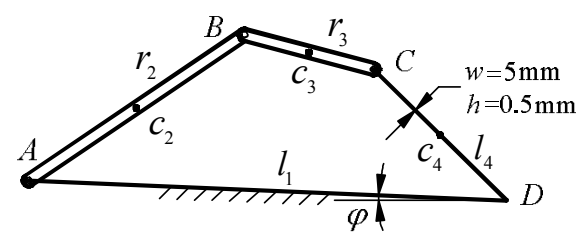

Fig. 3. Compliant bistable switch

Table 1. Pseudo-rigid model parameters

\begin{tabular}{cccccc}
\hline$r_{1}(\mathrm{~mm})$ & $r_{2}(\mathrm{~mm})$ & $r_{3}(\mathrm{~mm})$ & $l_{4}(\mathrm{~mm})$ & $\gamma$ & \\
\hline 26 & 14.8 & 7.6 & 10.6 & 0.85 & $2.6 \% 6$ \\
\hline
\end{tabular}

\subsection{Initial position influence}

According to Table 1, the calculation shows that the motion range of the driving link 2 is $-36.4^{\circ} \sim 36.4^{\circ}$, the motion range of the link 3 and the drived rocker 4 are $-65^{\circ} \sim 32^{\circ}$ and $-32^{\circ} \sim 57^{\circ}$, respectively. The angular displacement relationship curves of each member are shown in Fig.4.

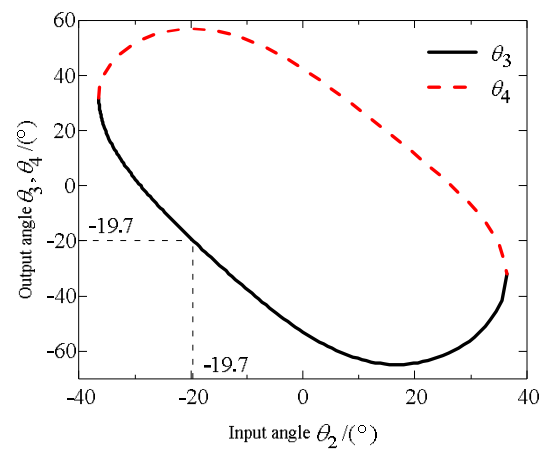

Fig. 4. Angular displacement curves of mechanism

When links 2 and 3 are collinear (such as $\theta_{2}=\theta_{3}=-19.7^{\circ}$ ), the mechanism is in an unstable equilibrium position. Then the two stable equilibrium positions of the mechanism should be distributed on both sides of the unstable equilibrium position, and the initial motion position of the mechanism should be one of its stable equilibrium positions. Therefore, according to the angular displacement curves of each member in Fig.4 (or calculated by Eq. (34)), the value range of $\theta_{40}$ can be determined to be $32^{\circ} \sim 57^{\circ}$.

During the movement of the mechanism, the work done by the driving torque $T_{\text {in }}$ on the link 2 and the deformation energy stored on the flexible link 4 form a functional conversion. Thus, the work done by the driving torque on the link 2 can be expressed as

$$
E_{\mathrm{P}}=\int_{\theta_{0}}^{\theta} T_{\mathrm{in}} \mathrm{d} \theta_{2}=\frac{1}{2} K_{\mathrm{d} 4}\left(\theta_{4}-\theta_{40}\right)^{2}
$$

Eq. (35) takes the derivative of $\theta_{2}$, we get

$$
T_{\text {in }}=K_{\mathrm{d} 4}\left(\theta_{4}-\theta_{40}\right) \frac{r_{2} \sin \left(\theta_{3}-\theta_{2}\right)}{r_{4} \sin \left(\theta_{3}-\theta_{4}\right)}
$$

It can be seen that the driving torque $T_{\text {in }}$ is numerically equal to the first derivative of the energy equation with respect to the driving variable, and the zero point of the derivative equation is the equilibrium position of the mechanism.

In Fig. 3, the material of the flexible link 4 is polypropylene, and the structural parameters and material properties are shown in Table 2. Then, the dynamic spring constant of the torsion spring in the corresponding pseudo-rigid body model is

$$
K_{\mathrm{d} 4}=\gamma K_{\varphi} \frac{E I}{l_{4}}=\gamma K_{\varphi} \frac{E b_{4} h_{4}{ }^{3}}{12 l_{4}}=1.33 \times 10^{-2} \mathrm{~N} \cdot \mathrm{m} / \mathrm{rad}
$$

Table 2. Parameters of flexible link

\begin{tabular}{rcccc}
\hline $\begin{array}{c}\text { Density } \\
\rho\left(\mathrm{Kg} / \mathrm{m}^{3}\right)\end{array}$ & $\begin{array}{c}\text { Width } \\
w_{4}(\mathrm{~mm})\end{array}$ & $\begin{array}{c}\text { Thicknes } \\
h_{4}(\mathrm{~mm})\end{array}$ & $\begin{array}{c}\text { Elastic } \\
\text { modulus } \\
E_{4}\left(\mathrm{~N} / \mathrm{m}^{2}\right)\end{array}$ & $\begin{array}{c}\text { Inertia moment } \\
I_{4}\left(\mathrm{~m}^{4}\right)\end{array}$ \\
\hline 910 & 5 & 0.5 & $1.35 \times 10^{9}$ & $5.21 \times 10^{-14}$ \\
\hline
\end{tabular}

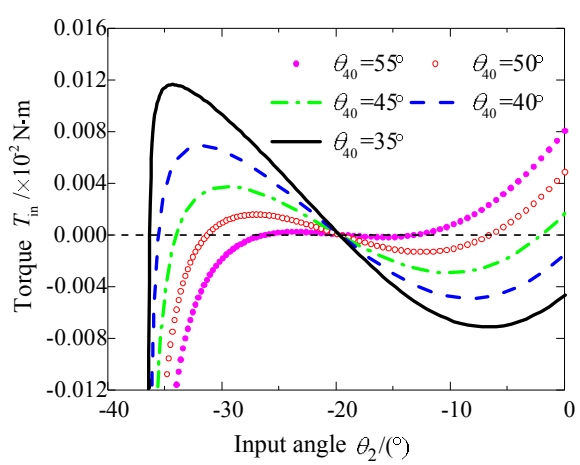

Fig. 5. Relation curve of $T_{\text {in }}$ and $\theta_{40}$

Now, the relationship curve between the driving torque $T_{\text {in }}$ of the link 2 and the initial position $\theta_{40}$ of the member 4 can be obtained from Eq. (36), as shown in Fig.5. The zero point of the driving torque $T_{\text {in }}$ corresponds to the two stable equilibrium positions and an unstable equilibrium position of the four-bar compliant mechanism, and the intersection point of all curves is the unstable equilibrium 
position. It can be seen that the driving torque $T_{\text {in }}$ of the link 2 and the motion range of the mechanism have an approximately inverse relationship with the initial angle $\theta_{40}$. If the installation space between the moving and static contacts of the bistable switch is taken into account, it is advisable that $\theta_{40}=40^{\circ}$. At this time, the two stable equilibrium positions of the mechanism are $\theta_{2}=-35.6^{\circ}$ and $\theta_{2}=1.5^{\circ}$, respectively.

\subsection{Influence of torsion spring stiffness}

Given that the compliant bistable switch is in the open state at the initial position $\theta_{20}=-35.6^{\circ}$, the selection range of the torsion spring stiffness is $0 \sim 0.02 \mathrm{~N} \cdot \mathrm{m} / \mathrm{rad}$, the relationship curve between the driving torque $T_{\text {in }}$ and the torsion spring stiffness $K_{\mathrm{d} 4}$, as shown in Fig. 6. It can be seen that no matter what the value of $K_{\mathrm{d} 4}$ is, the change trend of the driving torque $T_{\text {in }}$ in the motion range of the mechanism is the same, and the variation range of the driving torque increases with the increase of the torsion spring stiffness.

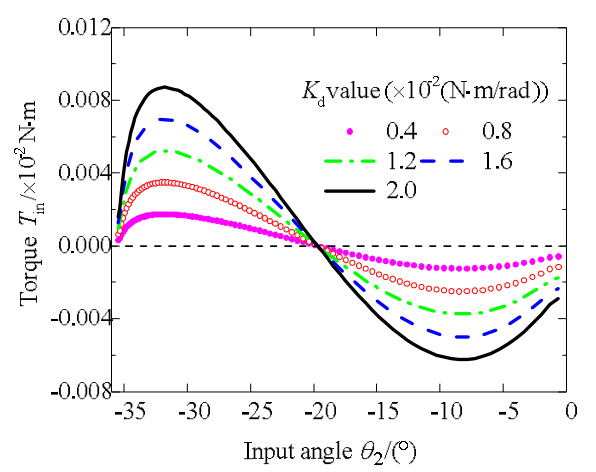

Fig. 6. Relation curve of $T_{\text {in }}$ and $K_{\mathrm{d} 4}$

The selection of the stiffness parameters of the flexible member in the compliant bistable switch depends on factors such as the drive mode, mechanical structure, energy consumption and control. At the same time, the key of bistable switch design is to select a suitable driving torque for the mechanism. The schematic diagram of the preliminarily designed compliant bistable switch structure is shown in Fig.7.

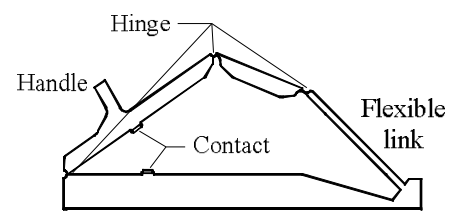

Fig. 7 Schematic diagram of compliant bistable switch

Meanwhile, the driving torque acting on the handle is

$$
T_{\text {in }}=0.0133 \times\left(\theta_{4}-\frac{2 \pi}{9}\right) \frac{14.8 \times \sin \left(\theta_{3}-\theta_{2}\right)}{9 \times \sin \left(\theta_{3}-\theta_{4}\right)}
$$

The compliant bistable switch shown in Fig. 7 is made of polypropylene and its initial structure and material parameters are shown in Tables 1 and 2. In the following, the flexible link is used as the optimization object, its structural parameters are taken as the design variables, and the maximum motion range and strain energy of the mechanism are taken as the goals to carry out the optimal design of compliant bistable switch.

\subsection{Motion range optimization}

(1) Design variables

Select the length of the flexible link and the initial motion position as design variables, we have

$$
\boldsymbol{x}=\left(x_{1}, x_{2}\right)^{\mathrm{T}}=\left(l_{4}, \theta_{20}\right)^{\mathrm{T}}
$$

(2) Objective function

One stable equilibrium position of the compliant bistable switch is its initial motion position (i.e., $\theta_{2}=\theta_{20}$ ), and the other stable equilibrium position can be expressed as

$$
\theta_{2}=2 \arctan \frac{r_{4} \sin \theta_{40}}{r_{1}+r_{4} \cos \theta_{40}}-\theta_{20}
$$

Based on reliability and installation space considerations, in order to maximize the contact distance of the compliant bistable switch, the angle between the two stable equilibrium positions needs to be maximized, namely

$$
f(\boldsymbol{x})_{\max }=\Delta \theta_{2}\left(l_{4}, \theta_{20}\right)=2\left|\arctan \frac{0.85 l_{4} \sin \theta_{40}}{r_{1}+0.85 l_{4} \cos \theta_{40}}-\theta_{20}\right|
$$

(3) Constraint conditions

1) Member length constraint

In the mechanism of compliant bistable switch shown in Fig. 3, if the frame length $r_{1}$ is the longest, $l_{4}$ must satisfy the inequality $r_{1} \leq r_{2}+r_{3}+0.85 l_{4}$, that is, 4.3 $\mathrm{mm} \leq l_{4} \leq 30.5 \mathrm{~mm}$; If the length of the flexible link $l_{4}$ is the longest, $l_{4}$ must satisfy the inequality $0.85 l_{4} \leq r_{1}+r_{2}+r_{3}$, that is, $30.5 \mathrm{~mm} \leq l_{4} \leq 56.9 \mathrm{~mm}$. Therefore, the value range of $l_{4}$ is $4.3 \mathrm{~mm} \leq l_{4} \leq 56.9 \mathrm{~mm}$. In addition, from Eq. (33), the value range of the length $l_{4}$ of the flexible link is $0<l_{4}$

\begin{tabular}{|c|c|c|c|}
\hline Type & \multicolumn{2}{|c|}{ Category condition } & Value range of $l_{4}$ \\
\hline 1 & longest link length & $l_{4}$ is the largest & $39 \mathrm{~mm}<l_{4} \leq 56.9 \mathrm{~mm}$ \\
\hline 2 & $\begin{array}{c}+ \text { shortest link } \\
\text { length }>\text { sum of the }\end{array}$ & $\begin{array}{c}r_{1} \text { is the largest, } l_{4} \text { is } \\
\text { the shortest }\end{array}$ & $4.3 \mathrm{~mm}<l_{4} \leq 8.8 \mathrm{~mm}$ \\
\hline 3 & $\begin{array}{l}\text { other two link } \\
\text { lengths }\end{array}$ & $\begin{array}{c}r_{1} \text { is the largest, } r_{3} \text { is } \\
\text { the shortest }\end{array}$ & $\begin{array}{c}8.8 \mathrm{~mm}<l_{4} \leq 22.1 \mathrm{~m} \\
\mathrm{~m}\end{array}$ \\
\hline 4 & $\begin{array}{l}\text { longest link length } \\
\text { sum of the other tw } \\
\text { the }\end{array}$ & $\begin{array}{l}\text { hortest link length } \leq \\
\text { ink lengths, and } r_{3} \text { is } \\
\text { ortest }\end{array}$ & $22.1 \mathrm{~mm} \leq l_{4} \leq 39 \mathrm{~mm}$ \\
\hline
\end{tabular}
or $22.1 \mathrm{~mm} \leq l_{4} \leq 39 \mathrm{~mm}$. In summary, the value of flexible link length $l_{4}$ is shown in Table 3 .

Table 3. Subdivision table of the value range of $l_{4}$

2) Initial position constraint

According to the value type of $l_{4}$ in Table 3 , the value 
range of variable $\theta_{2}$ is discussed in the following section.

For Type 1, the limit position of the mechanism occurs when the link 2 is collinear with the link 3 or the link 2 is overlap with the link 4, as shown in Fig.8. The value range of the variable $\theta_{2}$ can be obtained as

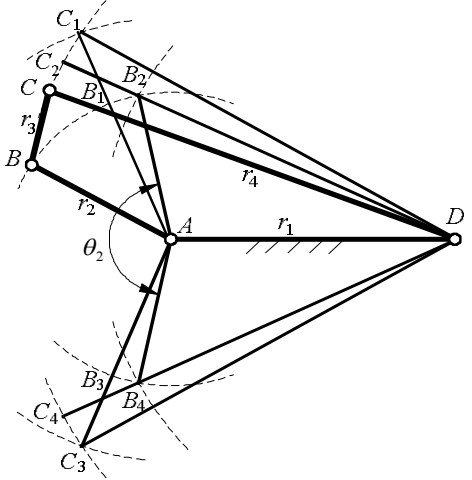

Fig. 8. No.1 limit position analysis of mechanism

$$
\left\{\begin{array}{l}
\arccos \frac{r_{1}^{2}+r_{2}^{2}-\left(r_{4}^{2}-r_{3}^{2}\right)}{2 r_{1} r_{2}} \leq \theta_{2} \leq \pi \\
\text { or } \\
-\pi \leq \theta_{2} \leq-\arccos \frac{r_{1}^{2}+r_{2}^{2}-\left(r_{4}^{2}-r_{3}^{2}\right)}{2 r_{1} r_{2}}
\end{array}\right.
$$

For Types 2 and 3, the limit position of the mechanism occurs when the link 2 is collinear with the link 3 or the link 3 is collinear with link 4, as shown in Fig.9. Then the value range of variable $\theta_{2}$ is

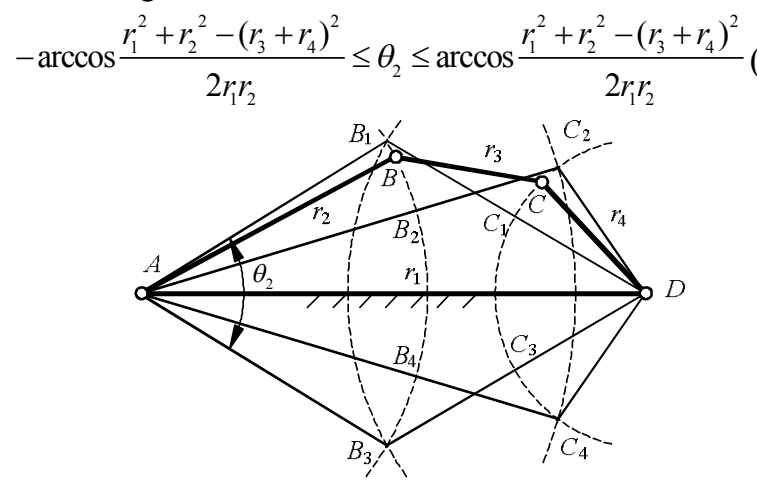

Fig. 9. No.2 limit position analysis of mechanism

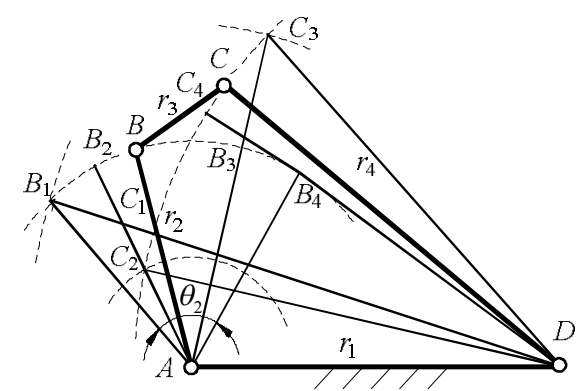

Fig. 10. No.3 limit position analysis of mechanism

For Type4, the limit position of the mechanism occurs when the link 2 and the link 3 are collinear or overlap, and when the link 3 and the link 4 are collinear or overlap, as shown in Fig. 10. So, the value range of variable $\theta_{2}$ is

$$
\arccos \frac{r_{1}^{2}+r_{2}^{2}-\left(r_{4}-r_{3}\right)^{2}}{2 r_{1} r_{2}} \leq \theta_{2} \leq \arccos \frac{r_{1}^{2}+r_{2}^{2}-\left(r_{3}+r_{4}\right)^{2}}{2 r_{1} r_{2}}
$$

(4) Optimization analysis

When the value range of $l_{4}$ is $4.3 \mathrm{~mm}<l_{4} \leq 8.8 \mathrm{~mm}$, the motion range of the mechanism is shown in Fig.11. It is not difficult to find that with the increase of $l_{4}$, the value range of the initial motion position $\theta_{20}$ of the mechanism, the change amplitude and the maximum value of the motion range of the mechanism are all increasing. When $l_{4}=8.8 \mathrm{~mm}$, the motion range of the mechanism (i.e., $\Delta \theta_{2}$ ) to obtain the maximum value of about $45.8^{\circ}$.

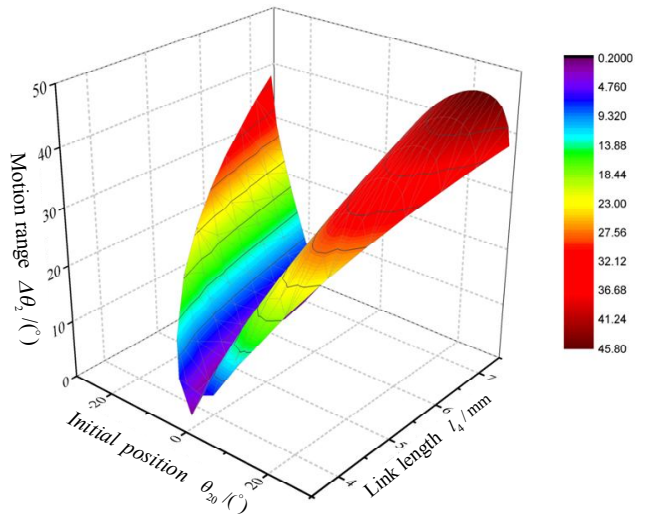

Fig. 11. Motion range of mechanism when $4.3 \mathrm{~mm}<l_{4} \leq 8.8 \mathrm{~mm}$

When the value range of $l_{4}$ is $8.8 \mathrm{~mm}<l_{4} \leq 22.1 \mathrm{~mm}$, the motion range of the mechanism is shown in Fig.12. It can be concluded that with the increase of $l_{4}$, the value range of the initial motion position $\theta_{20}$ becomes larger, and the motion range of the mechanism also increases slowly, but it does not change after increasing to a certain extent. The maximum motion range of the mechanism is about $61.8^{\circ}$ (at this time $l_{4}=14.4 \mathrm{~mm}$ ).

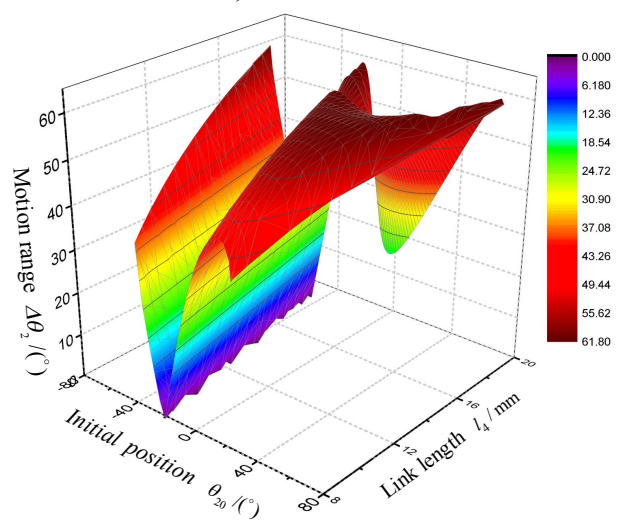

Fig. 12 Motion range of mechanism when $8.8 \mathrm{~mm}<l_{4} \leq 22.1 \mathrm{~mm}$

When the value range of $l_{4}$ is $22.1 \mathrm{~mm}<l_{4} \leq 39 \mathrm{~mm}$, the motion range of the mechanism is shown in Fig.13. Similarly, with the increase of $l_{4}$, the value range of the initial position $\theta_{20}$ of the mechanism also increases, but the motion range of the mechanism basically remains unchanged, and the maximum value of the motion range of the mechanism is about $61.8^{\circ}$. 


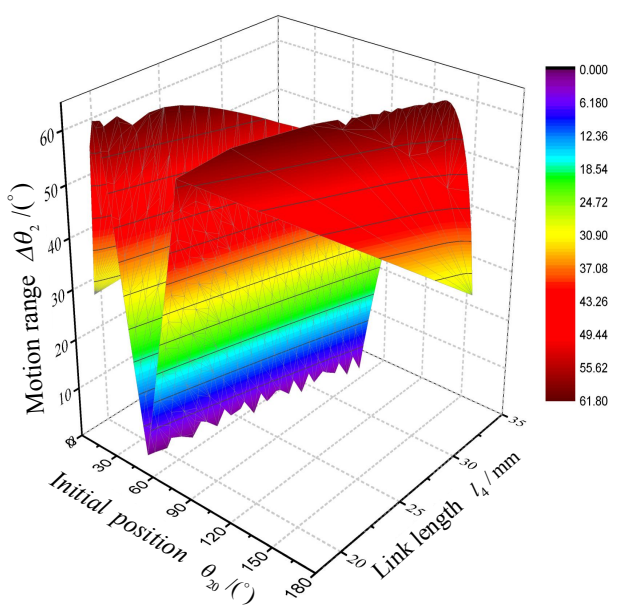

Fig. 13 Motion range of mechanism when $22.1 \mathrm{~mm}<l_{4} \leq 39 \mathrm{~mm}$

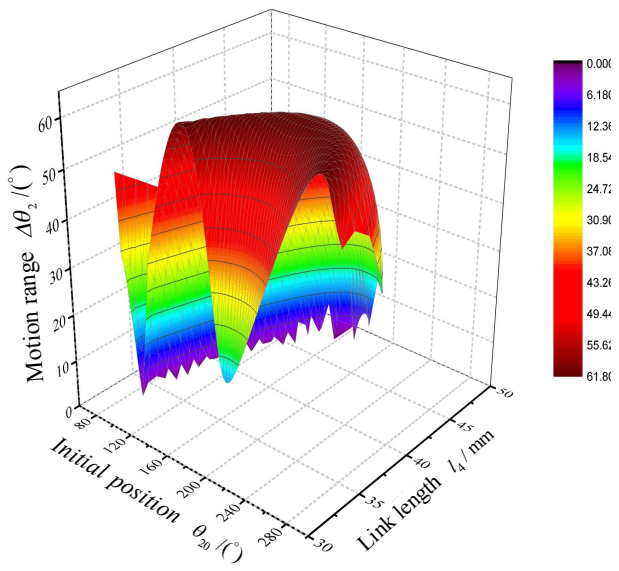

Fig. 14 Motion range of mechanism when $39 \mathrm{~mm}<l_{4} \leq 56.9 \mathrm{~mm}$

When the value range of $l_{4}$ is $39 \mathrm{~mm}<l_{4} \leq 56.9 \mathrm{~mm}$, the motion range of the mechanism is shown in Fig.14. It can be seen that with the increase of $l_{4}$, the value range of the initial motion position $\theta_{20}$ gradually decreases, but the motion range of the mechanism first remains unchanged and then decreases, and the maximum value of the motion range of the mechanism is about $61.8^{\circ}$.

According to the foregoing analysis, taking into account factors such as the ease of control and mechanical efficiency of the compliant mechanism, $14.4 \mathrm{~mm}<l_{4} \leq 16.2 \mathrm{~mm}$ and $39 \mathrm{~mm}<l_{4} \leq 44.5 \mathrm{~mm}$ are selected as the value ranges for mechanism parameter optimization. Then, the optimal solution with the goal of maximizing the motion range of the mechanism can be obtained, as shown in Table 4 . Note that if the value of $l_{4}$ is too large, the stability of the mechanism will become worse.

Table 4. Optimization results of $l_{4}$

\begin{tabular}{|c|c|c|c|}
\hline$l_{4} / \mathrm{mm}$ & $\begin{array}{l}\text { Optimization } \\
\text { solution } / \mathrm{mm}\end{array}$ & $\theta_{20} /\left(^{\circ}\right)$ & $\Delta \theta_{2} /\left(^{\circ}\right)$ \\
\hline $14.4<l_{4} \leq 16.2$ & $l_{4}=16.2$ & $-23.6 \sim 23.7$ & 61.8 \\
\hline $39<l_{4} \leq 44.5$ & $l_{4}=44.5$ & $\begin{array}{c}167.1 \sim 180 \text { or } \\
-180 \sim 167.3\end{array}$ & 61.8 \\
\hline
\end{tabular}

\subsection{Strain energy optimization}

Taking the cross-sectional parameters of the flexible link as the design variable, the optimal design of the strain energy performance of the compliant bistable switch is carried out.

(1) Design variables

Taking the cross-section parameters of the flexible link as design variables, we get

$$
\boldsymbol{x}=\left(x_{1}, x_{2}\right)^{\mathrm{T}}=\left(w_{4}, h_{4}\right)^{\mathrm{T}}
$$

where, $w_{4}$ and $h_{4}$ are the cross-sectional width and thickness of the flexible link, respectively.

(2) Objective function

The strain energy of the mechanism is

$$
E_{\mathrm{p}}=\frac{1}{24} \gamma K_{\varphi} E w_{4} h_{4}^{3}\left(\theta_{4}-\theta_{40}\right)^{2}
$$

When the initial motion position and motion range parameters of the mechanism are given, the strain energy of the mechanism is only determined by the width and thickness parameters of the cross section of the flexible link. Thus, the objective function can be expressed as

$$
f(x)=f\left(w_{4}, h_{4}\right)=w_{4} h_{4}{ }^{3}
$$

(3)Constraint conditions

According to experience(See references $[1,13])$, the optimal solution range of $w_{4}$ and $h_{4}$ are given as $2 \mathrm{~mm} \sim 6 \mathrm{~mm}$ and $0.1 \mathrm{~mm} \sim 1 \mathrm{~mm}$, respectively. At the same time, in order to improve the ability of the flexible link to store strain energy, the first-order natural frequency of the mechanism is set between $45 \mathrm{~Hz}$ and $60 \mathrm{~Hz}$. Then the constraint conditions can be expressed as

$$
\left\{\begin{array}{l}
\mathrm{g}_{1}(x)=f-60 \leq 0 \\
\mathrm{~g}_{2}(x)=45-f \leq 0 \\
\mathrm{~g}_{3}(x)=\sigma-28.6 \leq 0 \\
g_{4}(x)=2-w_{4} \leq 0 \\
g_{5}(x)=w_{4}-6 \leq 0 \\
g_{6}(x)=h_{4}-1 \leq 0 \\
g_{7}(x)=0.1-h_{4} \leq 0
\end{array}\right.
$$

(4) Optimization Results

By solving equations (44), (46) and (47), the optimization results can be obtained, as shown in Table 5. The results show that the strain energy performance of the optimized compliant bistable switch is increased by about $11.10 \%$, and the maximum stress of the flexible link is also improved to a large extent.

Table 5. Optimization results based on strain energy

\begin{tabular}{cccccc}
\hline $\begin{array}{c}\text { Serial } \\
\text { number }\end{array}$ & $\begin{array}{c}w_{4} \\
/ \mathrm{mm}\end{array}$ & $h_{4} / \mathrm{mm}$ & $\begin{array}{c}\sigma_{\max } \\
/ \mathrm{MPa}\end{array}$ & $f / \mathrm{Hz}$ & $\begin{array}{c}\text { Strain } \\
\text { energy } \\
\text { increment } \\
/(\%)\end{array}$ \\
\hline 1 & $5.0 \sim 5.6$ & 0.24 & 11.066 & 57.874 & $11.06 \sim 12.39$ \\
2 & $5.7 \sim 6$ & 0.23 & 10.605 & 55.495 & $11.10 \sim 11.70$ \\
\hline
\end{tabular}

\section{Conclusion}


The bistable characteristics of a four-bar compliant mechanism with a flexible member were analyzed. Taking a compliant bistable switch as an example, the driving characteristics and structural parameter optimization of the four-bar compliant mechanism were carried out. The conclusions are as follows:

(1) The condition for the existence of bistable characteristics of a four-bar compliant mechanism with one flexible member is that the sum of the lengths of the two links connected by the flexible joint should be greater than the sum of the lengths of the other two links, or the difference of the lengths of the two links connected by flexible joints should be less than the difference of the lengths of the other two links.

(2) The length parameter and initial motion position of the flexible member in the four-bar compliant mechanism have an important influence on the kinematics and driving characteristics of the mechanism.

(3) By optimizing the structural parameters such as the length and cross section of the flexible member in the four-bar compliant mechanism, the kinematics and dynamic characteristics of the mechanism can be improved.

\section{References}

[1] LIU Shanzeng, DAI Jiansheng, LI Aimin, SUN Zhaopeng, FENG Shizhe, CAO Guohua. Analysis of Frequency Characteristics and Sensitivity of Compliant Mechanisms[J]. Chinese Journal of Mechanical Engineering, 2016, 29(4): 680-693.

[2] HOWELL L L, MIDHA A. Parametric deflection approximations for end loaded large deflection beams in compliant mechanisms [J]. Transaction of the ASME, Journal of Mechanisms in Design, 1995, 117(3): 156-165.

[3] JENSEN B, HPWELL L. Identification of compliant pseudo-rigid-body four-link mechanism configurations resulting in bistable behavior [J]. Journal of Mechanical Design, 2003, 125(11): 701-708.

[4] HAN Qi. On accurate modeling of tensural muiltistable compliant mechanisms [D]. Xian: Xidian University, 2018. (in Chinese)

[5] TODD B, PHILLIPS M, SCHULTZ S M, HAWKINS A R, JENSEN B D. Low-cost RFID threshold shock sensors [J]. IEEE Sensors Journal, 2009, 9 (4): 464-469.

[6] KIM G W, KIM J. Compliant bistable mechanism for low frequency vibration energy harvester inspired by auditory hair bundle structures[J]. Smart Materials and Structures, 2013, 22(1): 014005.

[7] JUNG S P, JUNG G P, KOH J S, LEE D U, CHO K J. Fabrication of composite and sheet metal laminated bistable jumping mechanism [J]. ASME Journal of Mechanisms and Robotics, 2015,7(7): 021010.

[8] VINCENT Chalvet, YASSINE Haddab, PHILIPPE Lutz. A microfabricated planar digital microrobot for precise positioning based on bistable modules [J]. IEEE Transaction on Robotics, 013, 29 (3): 641-649.

[9] HETRIK J A, KOTA S. An energy formulation for parametric size and shape optimization of compliant mechanisms [J]. Transaction of the ASME, Journal of Mechanisms in Design, 1999, 121(3): 229-233.

[10] ZHAN Jinqing, PENG Yiping, LIU Min, HUANG Zhichao. Topological design of continuum structure with multiple performance constraints J]. Computer Integrated Manufacturing
Systems, https://kns.cnki.net/kcms/detail/11. 5946.tp.20201203. 0950.002.html. (in Chinese)

[11] WANG Nianfeng, GUO Hao, CHEN Bicheng, CUI Chaoyu, ZHANG Xianmin. Integrated Design of Actuation and Mechanism of Dielectric Elastomers Using Topology Optimization Based on Fat Bezier Curves [J]. Soft Robotics, 2019, 6(5): 644-656.

[12] PEI Xu, YU Jingjun, ZONG Guanghua, BI Shusheng. Design of compliant straight-line mechanisms using flexural joints [J]. Chinese Journal of Mechanical Enginering, 2014, 27(1): 146-153.

[13] WANG Wenjing, YU Yueqing. Dynamic analysis of compliant mechanisms based on finite element method [J]. Journal of Mechanical Engineering, 2010, 46(9): 79-86.

[14] LI Bo, SUN Wenjie, JIANG Lei, MA Fulei, CHEN Guimin. Research progress of electroactive bistable mechanism and its application in soft robots [J]. Journal of Mechanical Engineering, 2020, 56(19): 43-52.

\section{Biographical notes}

LIU Shanzeng, born in 1977, is currently an associate professor at China University of Mining and Technology, China. He received his $\mathrm{PhD}$ degree from Beijing University of Technology, China, in 2009. His research interests include mechanism, robotics and mechachonics engineering.

Tel: +86-516-83892760; E-mail: liushanzeng@163.com

SHEN Gang, born in 1982, is currently a professor and a $\mathrm{PhD}$ candidate supervisor at China University of Mining and Technology, China. He received $\mathrm{PhD}$ degree from Harbin Institute of Technology, China, in 2011.

E-mail: shenganghit@163.com

LI Yunwang, born in 1980, is currently an associate professor at China University of Mining and Technology, China.

E-mail: yunwangli@cumt.edu.cn

SUN Zhaopeng, born in 1988. He received his Master's degree in mechanical engineering China University of Mining and Technology, China. His research interests include mechanism and mechachonics engineering.

E-mail: szp19881109@126.com

\section{Declarations}

\section{Availability of data and materials}

All data generated or analysed during this study are included in this published article.

\section{Competing interests}

The authors declare that they have no competing interests.

\section{Funding}

Project Funded by the Priority Academic Program

Development of Jiangsu Higher Education Institutions (PAPDJX02).

\section{Authors' contributions}

LIU Shanzeng and SUN Zhaopeng carried out theoretical derivation, data analysis and paper writing. SHEN Gang reviewed the paper and suggested the structure of the paper. LI Yunwang proposed to revise the paper. All authors read and approved the final manuscript.

\section{Acknowledgements}

Not applicable. 
Figures

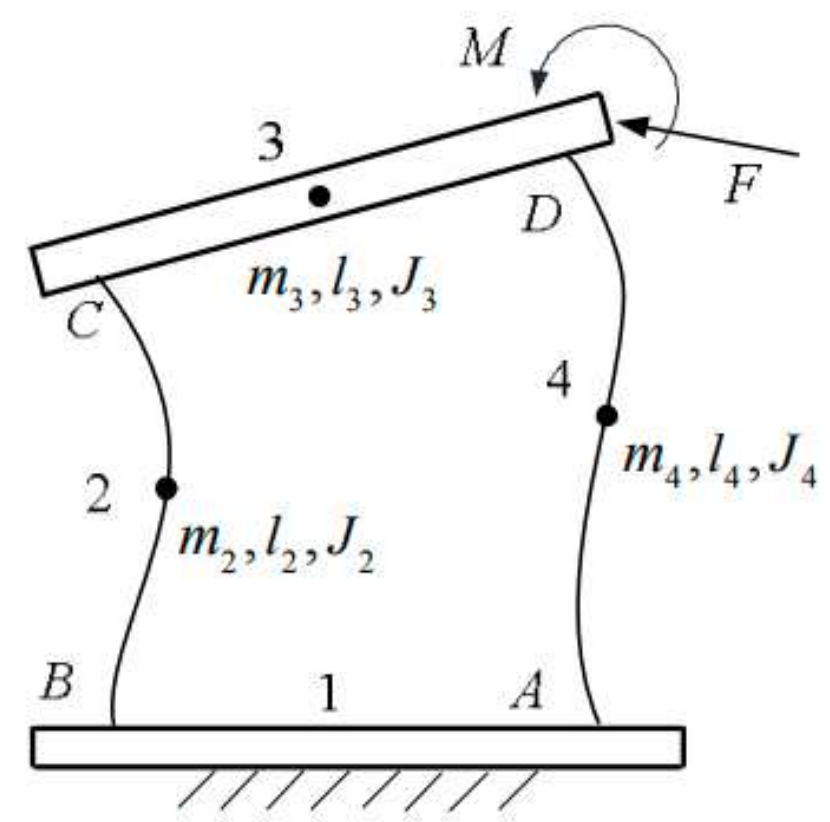

(a) Structural diagram

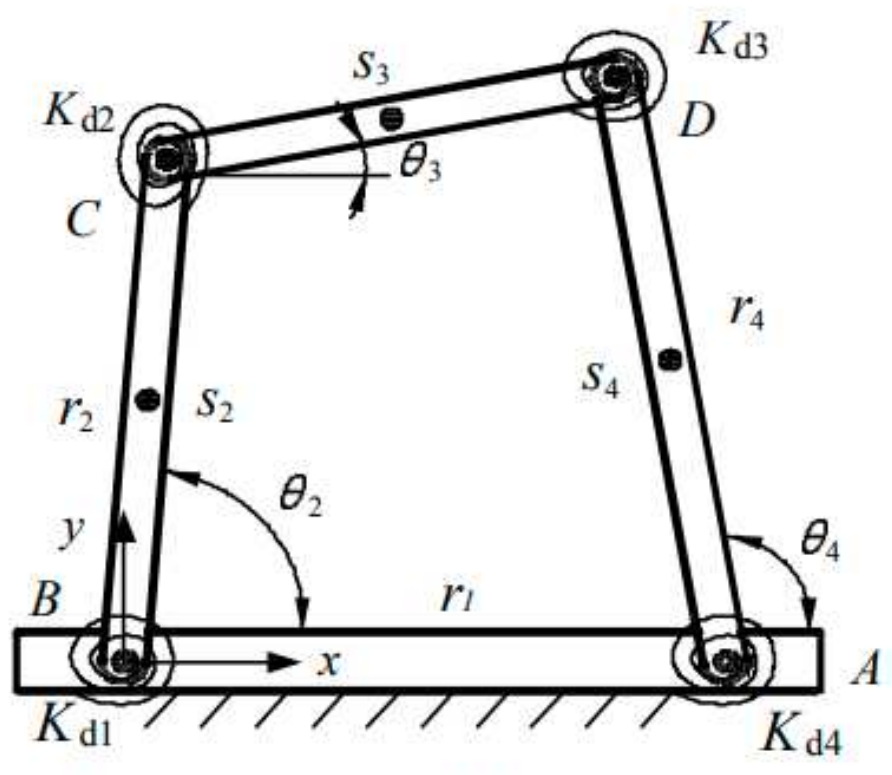

(b) Pseudo-rigid body model

Figure 1

Four-bar compliant mechanism

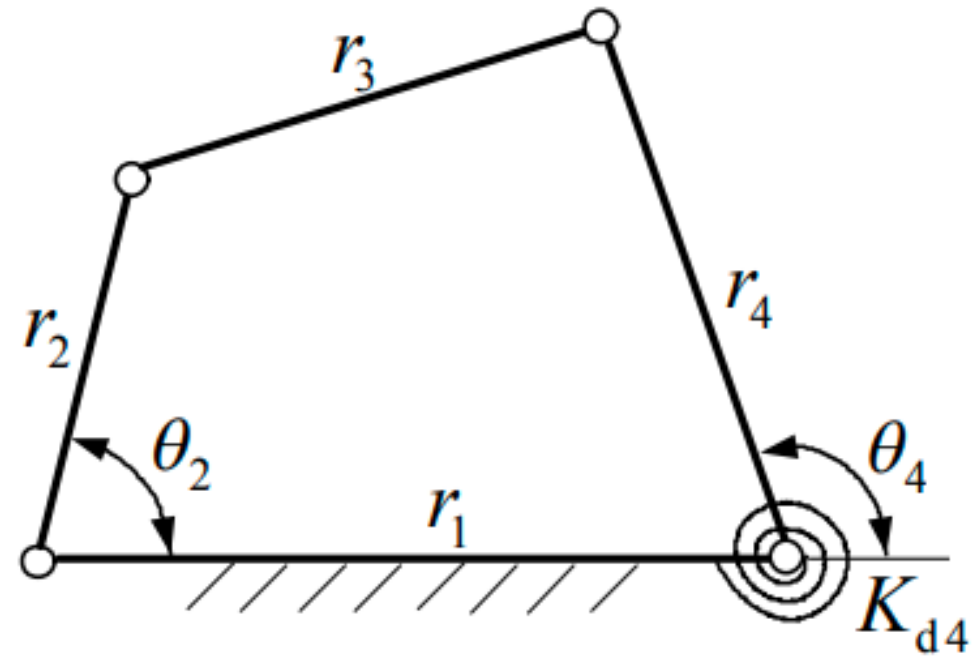

Figure 2

Pseudo-rigid body model of four-bar compliant mechanism with one flexible member 


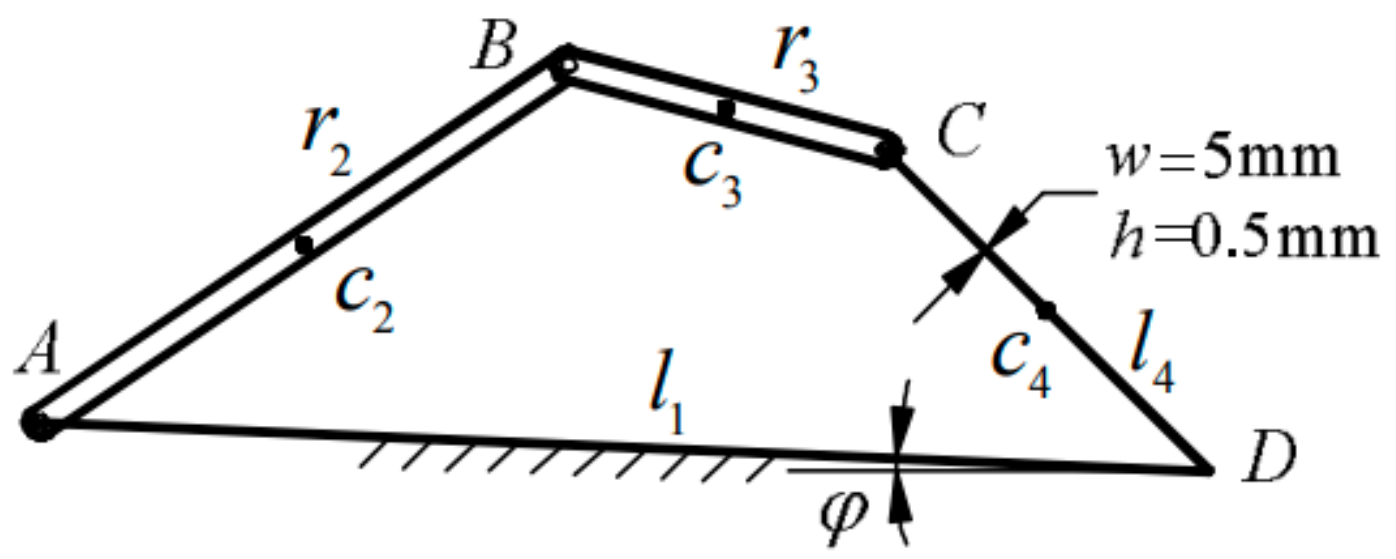

Figure 3

Compliant bistable switch

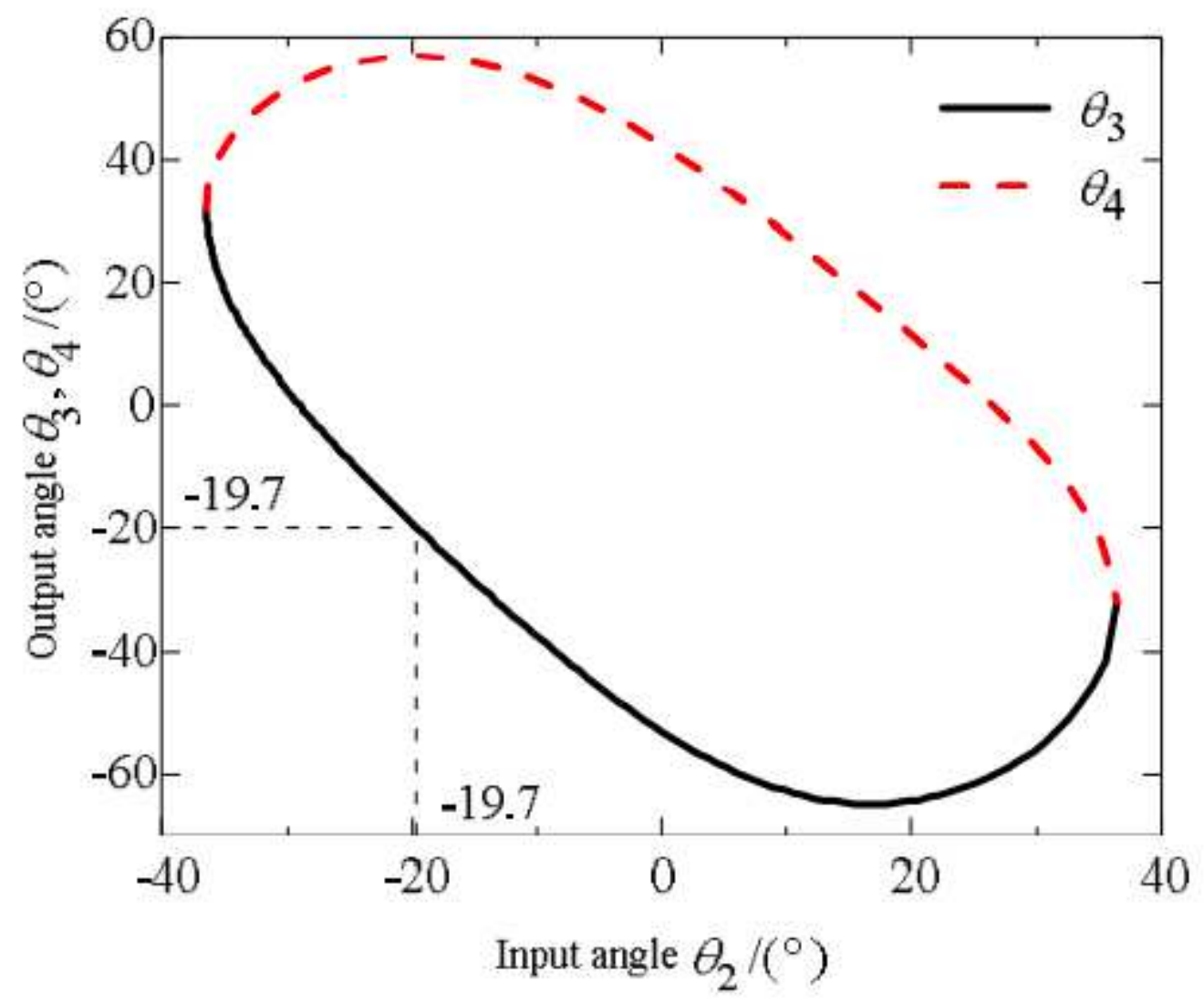

Figure 4

Angular displacement curves of mechanism 


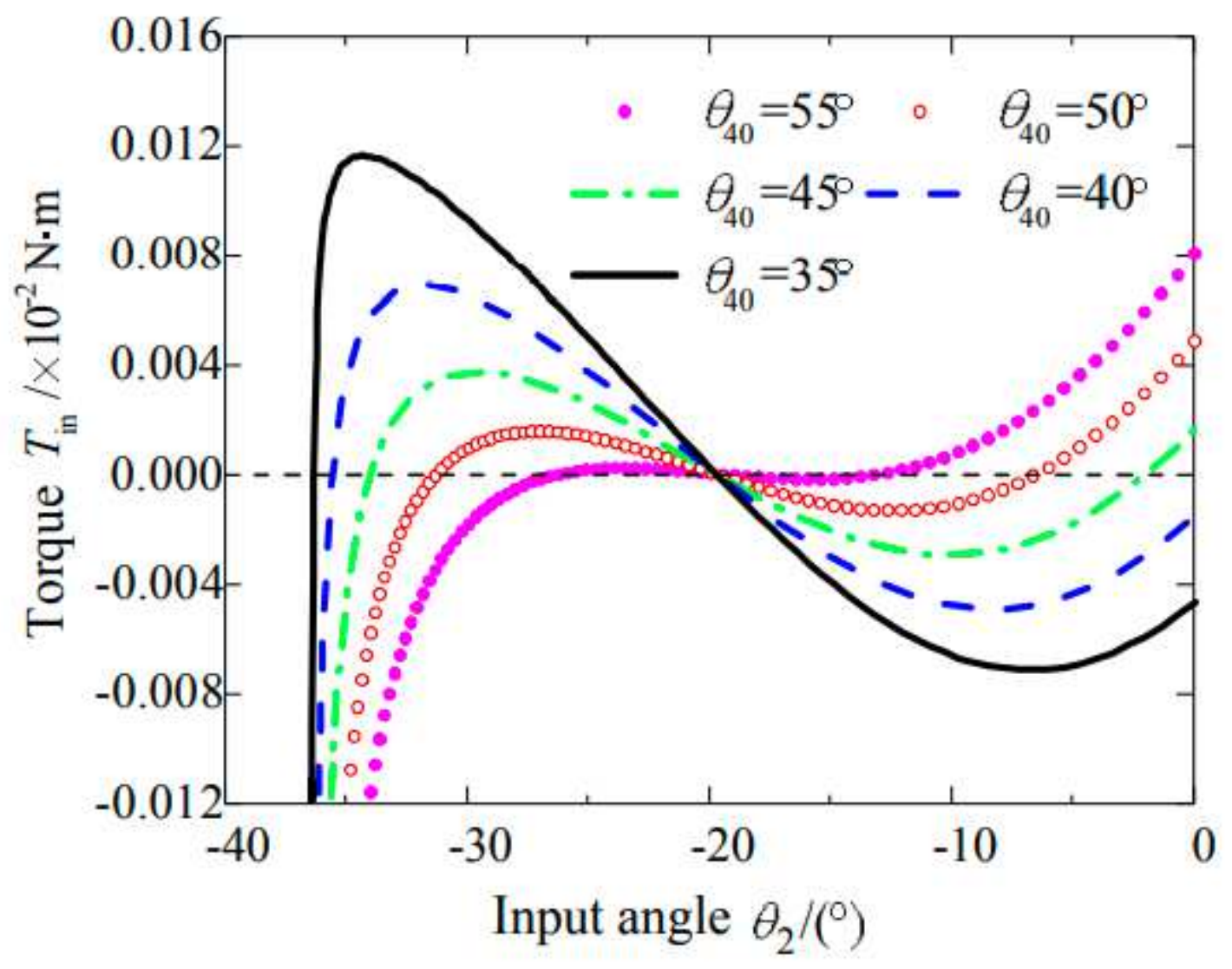

Figure 5

Relation curve of Tin and $\theta 40$ 


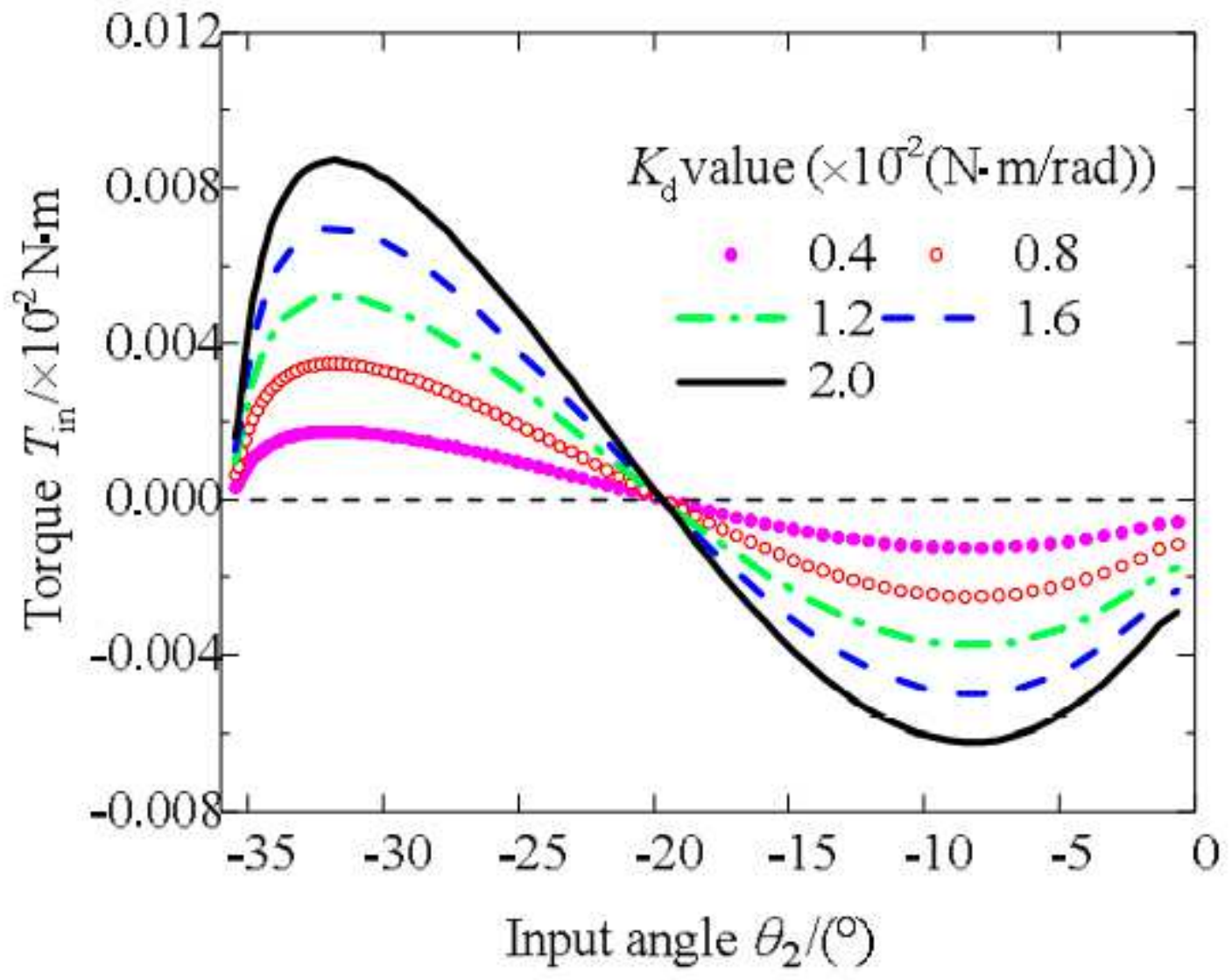

Figure 6

Relation curve of Tin and $\mathrm{Kd} 4$

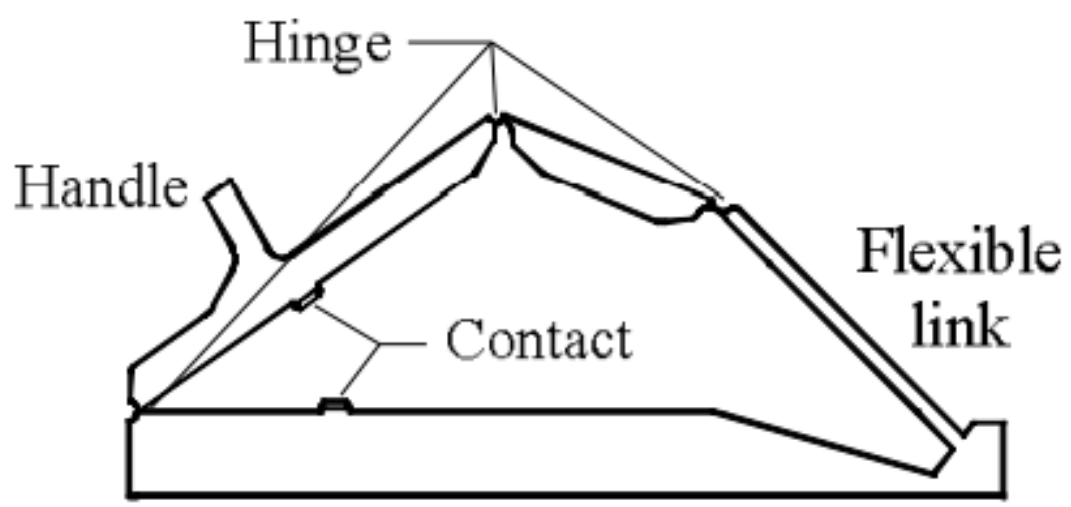

Figure 7

Schematic diagram of compliant bistable switch 


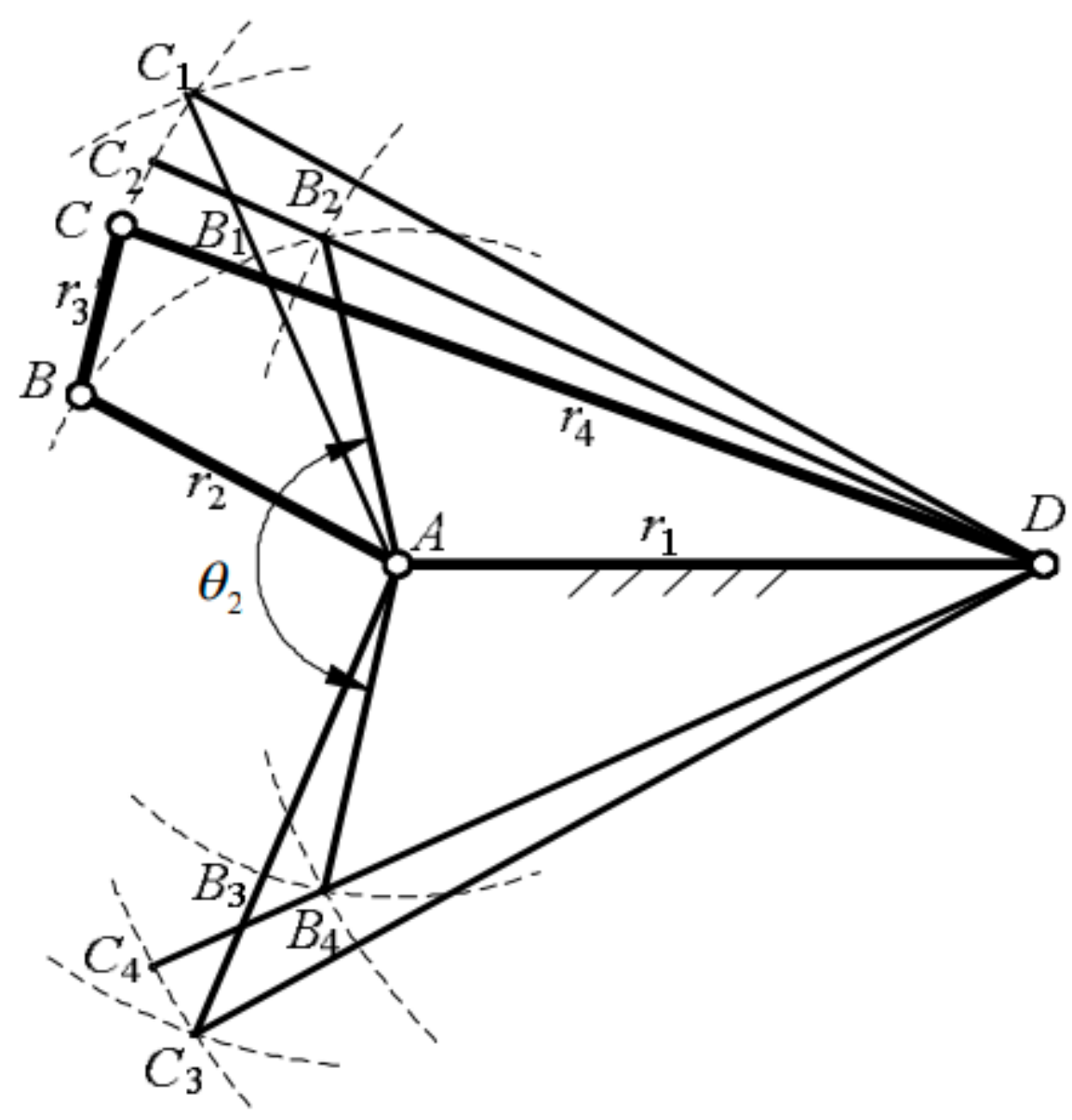

Figure 8

No.1 limit position analysis of mechanism

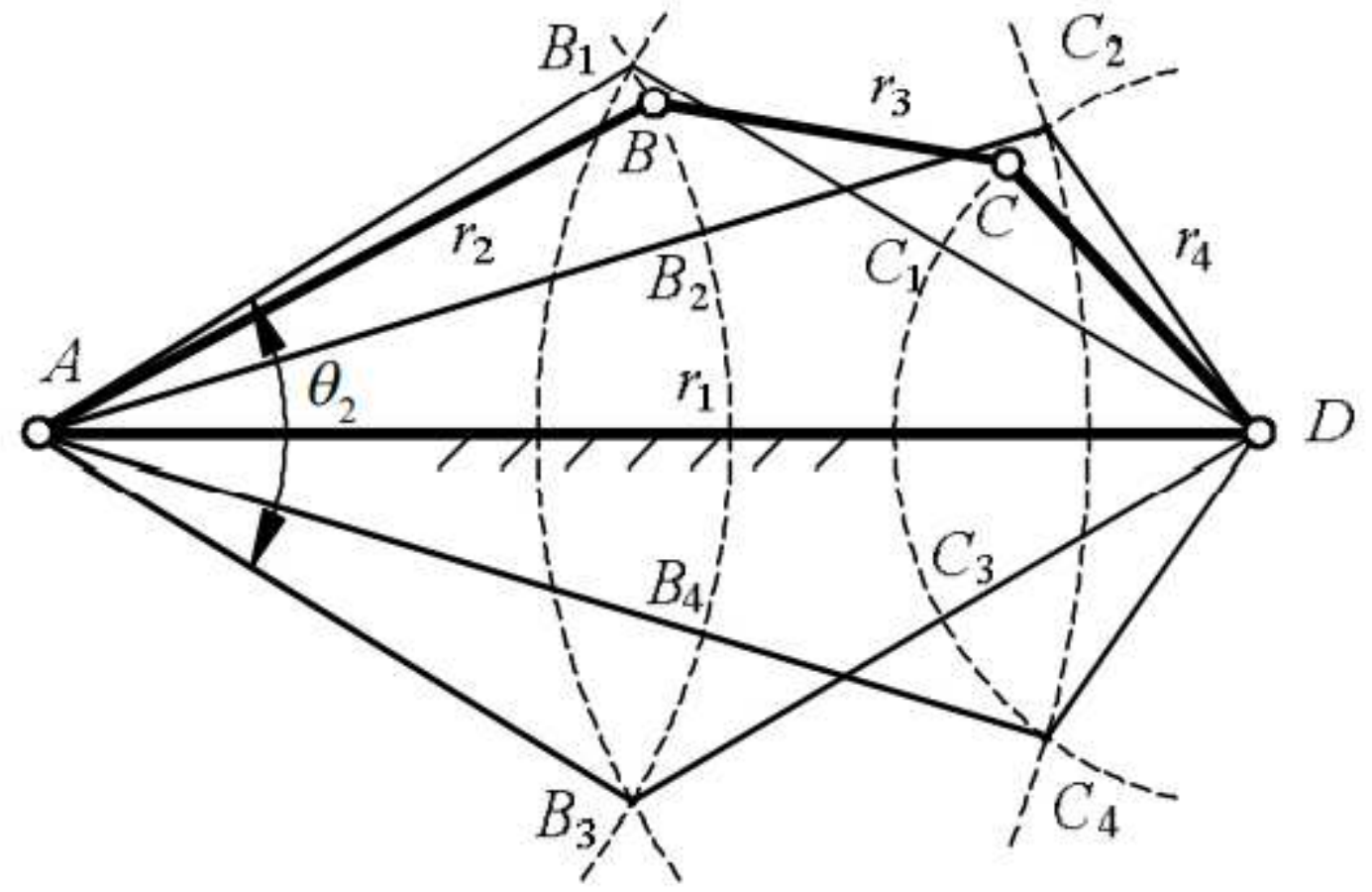

Figure 9 
No.2 limit position analysis of mechanism

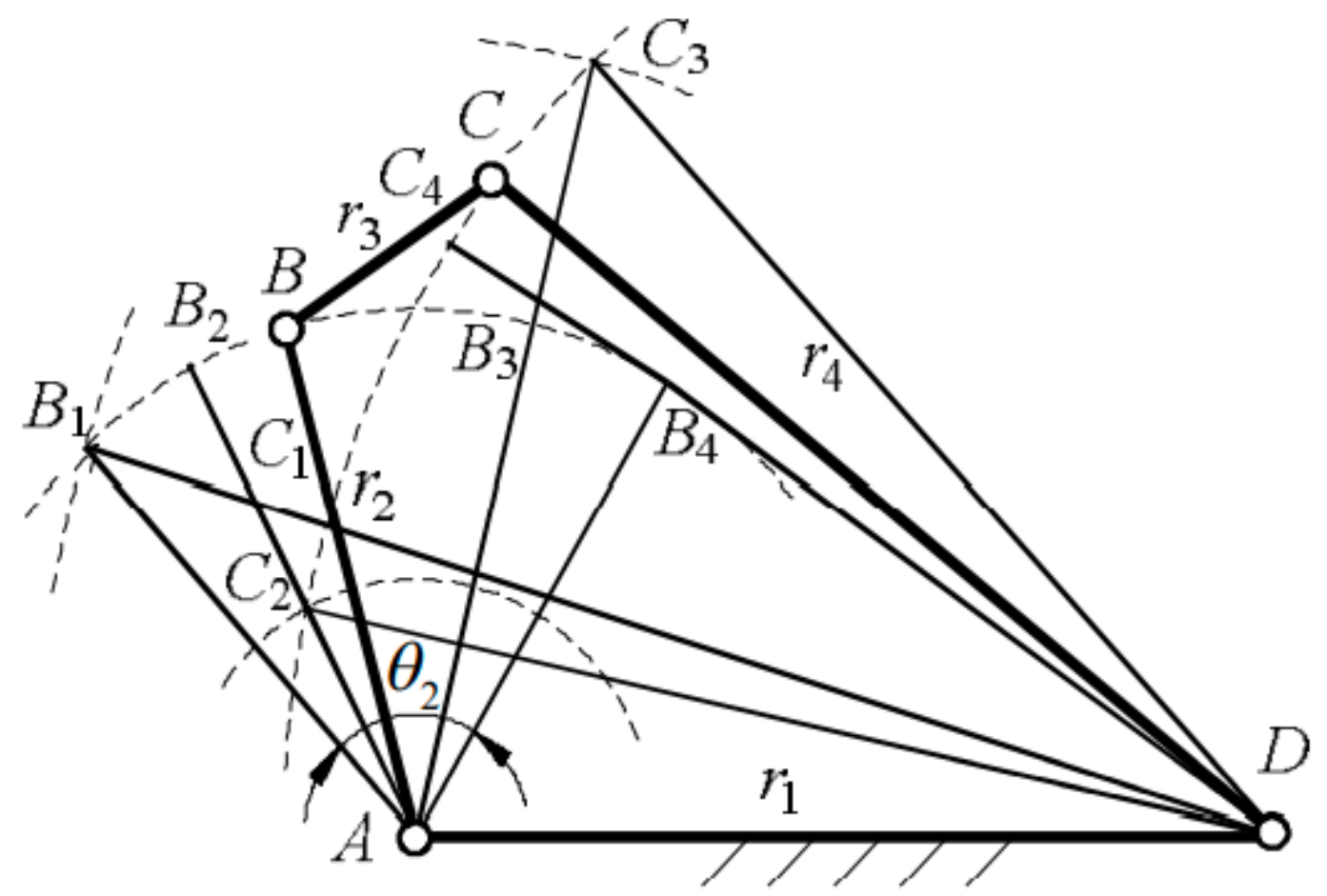

Figure 10

No.3 limit position analysis of mechanism 


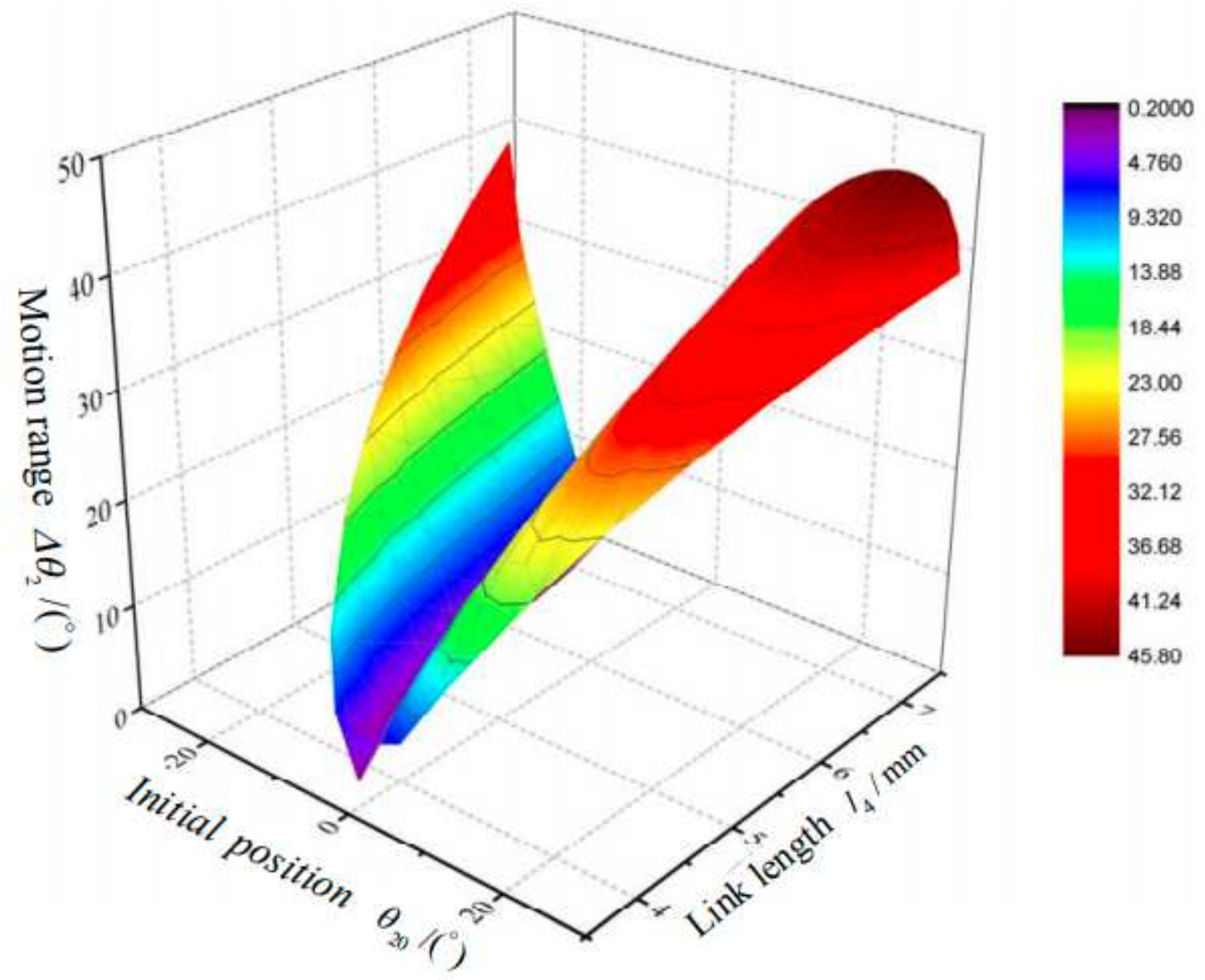

Figure 11

Motion range of mechanism when $4.3 \mathrm{~mm}<14 \leq 8.8 \mathrm{~mm}$ 


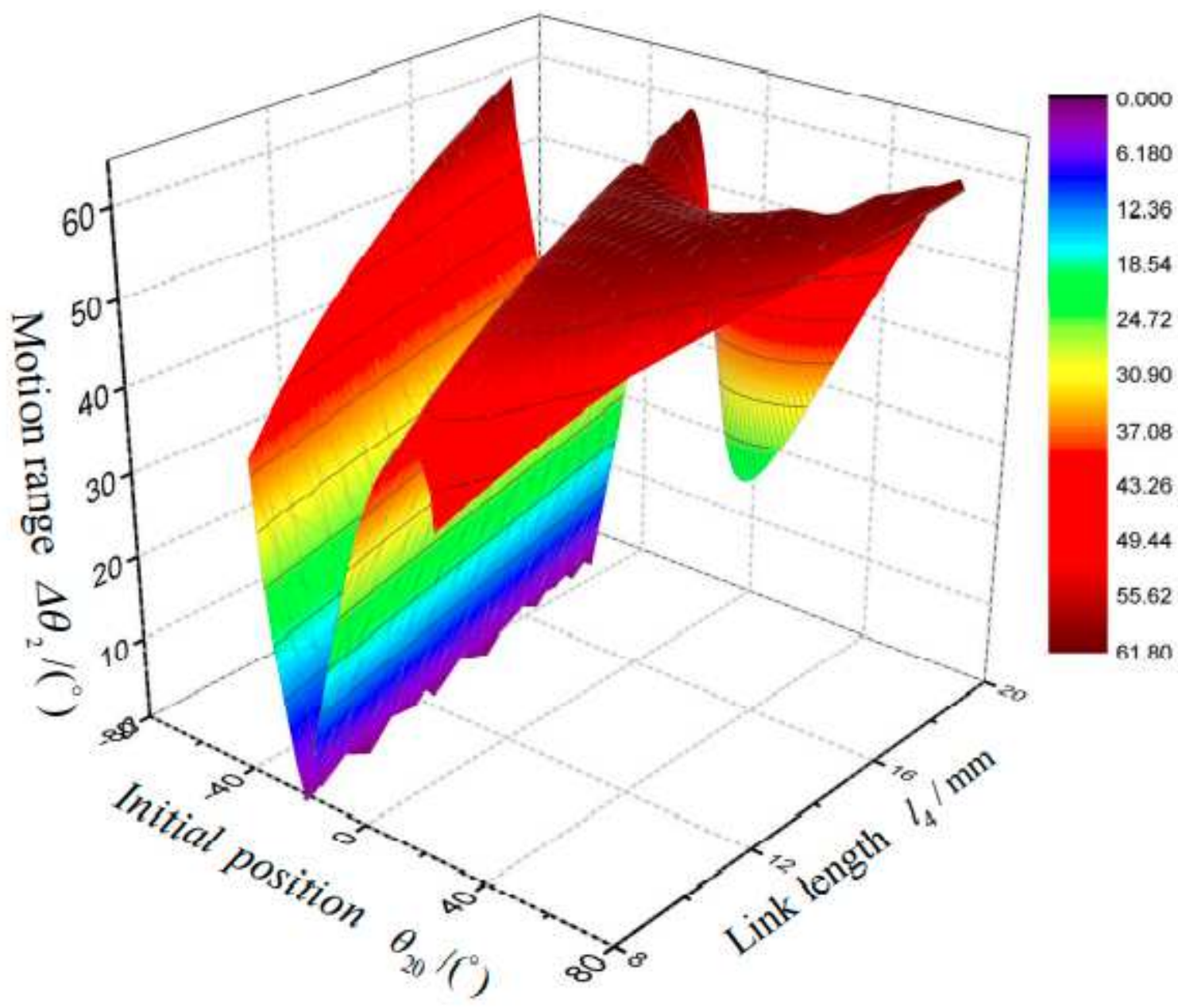

Figure 12

Motion range of mechanism when $8.8 \mathrm{~mm}<14 \leq 22.1 \mathrm{~mm}$ 


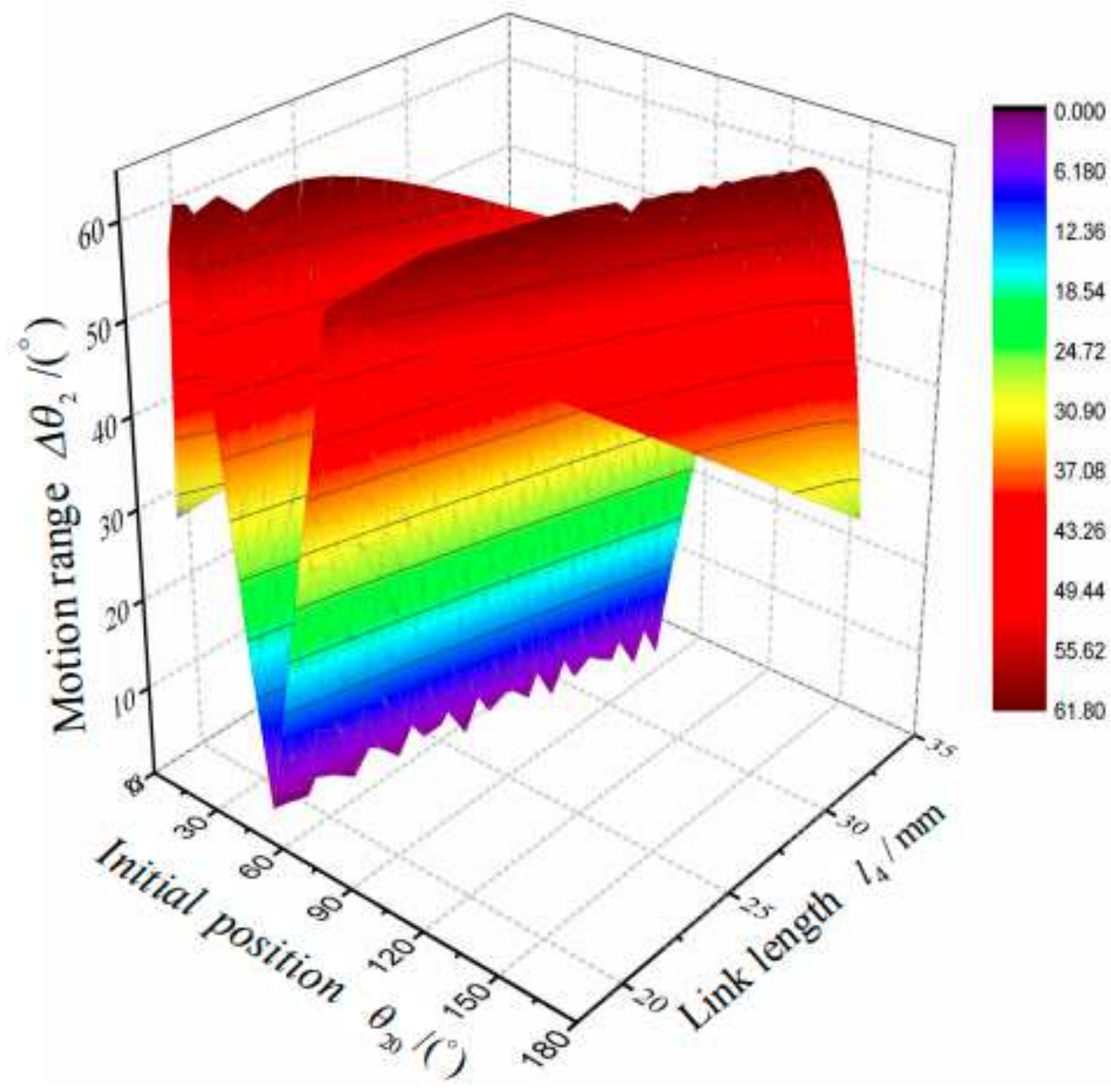

Figure 13

Motion range of mechanism when $22.1 \mathrm{~mm}<14 \leq 39 \mathrm{~mm}$ 


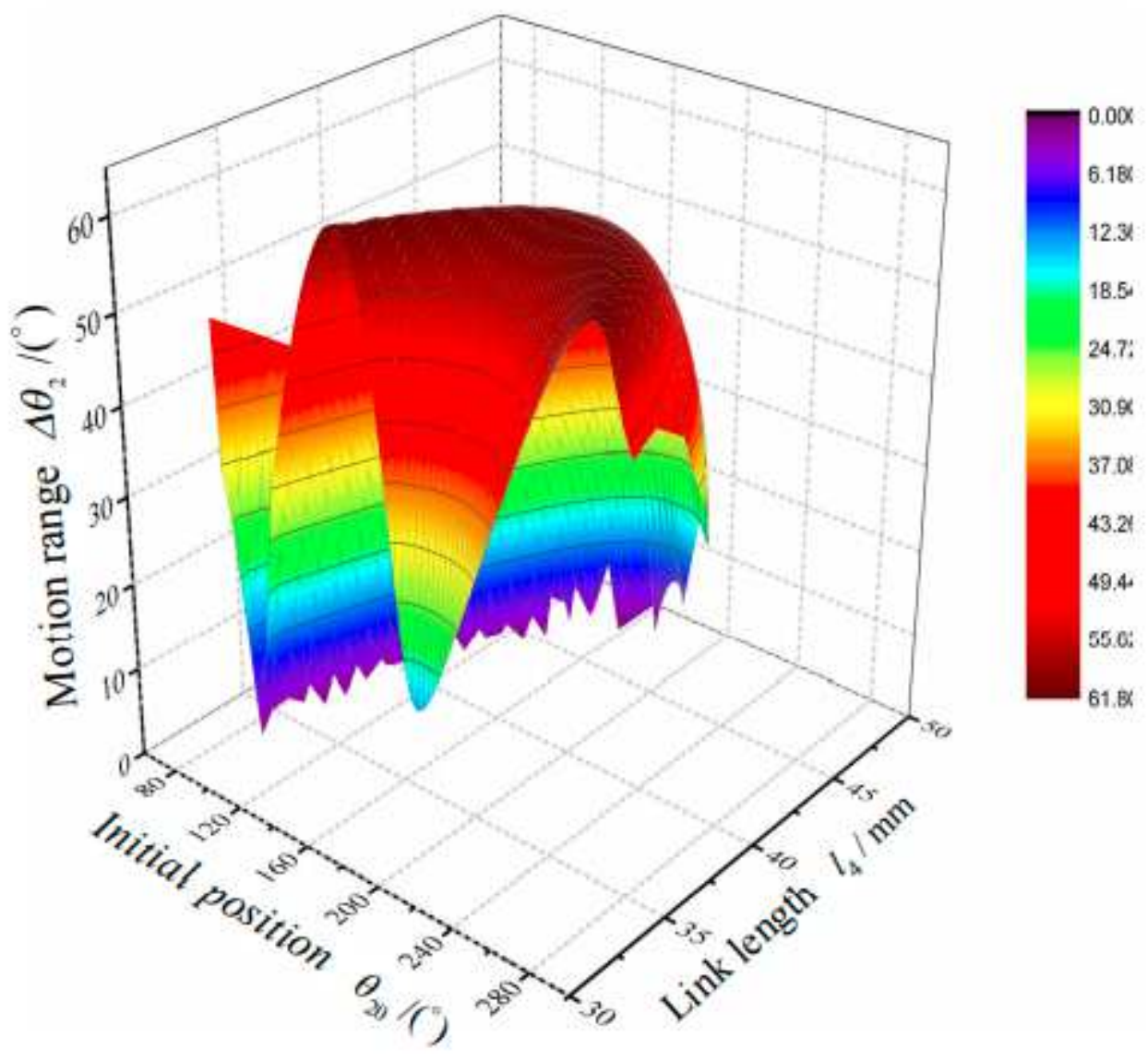

Figure 14

Motion range of mechanism when $39 \mathrm{~mm}<\mid 4 \leq 56.9 \mathrm{~mm}$ 